\title{
MULHERES EM REDE: CONECTANDO SABERES SOBRE PLANTAS ALIMENTÍCIAS DO CERRADO E DO PANTANAL
}

\section{WOMEN IN NETWORK: CONNECTING KNOWLEDGE ON CERRADO AND PANTANAL FOOD PLANTS}

\author{
Ieda Maria BORTOLOTTO ${ }^{1}$; Nathália Eberhardt ZIOLKOWSKI ${ }^{2}$; Rosane Juraci \\ Bastos GOMES ${ }^{3}$; Fernanda Savicki de ALMEIDA ${ }^{4}$; Raquel Pires CAMPOS ${ }^{5}$; Camila AOKI ${ }^{1,6}$ \\ Programa de Pós-Graduação em Biologia Vegetal, Instituto de Biociências. Universidade Federal de Mato Grosso do Sul, Campo \\ Grande, MS, Brasil. ${ }^{2}$ Ecoa - Ecologia e Ação, Campo Grande, MS, Brasil. ${ }^{3}$ Unicafes - União Nacional das Cooperativas da Agricultura \\ Familiar e Economia Solidaria, Brasília, DF, Brasil. ${ }^{4}$ Fundação Oswaldo Cruz - FIOCRUZ Mato Grosso do Sul, Campo Grande, MS, Brasil. \\ ${ }^{5}$ Faculdade de Farmácia, Engenharia de Alimentos e Nutrição. Universidade Federal de Mato Grosso do Sul, Campo Grande, MS, Brasil. ${ }^{6}$ \\ Universidade Federal de Mato Grosso do Sul, Campus de Aquidauana, Aquidauana MS, Brasil.*iedamaria.bortolotto@gmail.com
}

Submitted: 15/11/2020; Accepted: 01/03/2021; Published: 15/04/2021

\section{RESUMO}

O objetivo deste trabalho é discutir a ação das mulheres na produção de alimentos a partir de plantas nativas e a importância da rede que as conectam em Mato Grosso do Sul. Como objetivos específicos, procuramos identificar e analisar: o histórico de projetos nesta temática; as demandas que surgiram nas comunidades extrativistas; as estratégias de criação e fortalecimento da rede que conecta as mulheres e seus saberes; os principais desafios para a construção da rede e a importância das mulheres em relação aos temas abordados. Os dados foram obtidos por meio de análise documental, com consulta a relatórios técnico-científicos (e sites) de projetos de extensão e de pesquisa produzidos pela Universidade Federal de Mato Grosso do Sul e ONGs. As pesquisas foram desenvolvidas a partir de observação participante e mapeamento participativo em comunidades rurais e urbanas. Todos os projetos (pesquisa ou extensão) que resultaram nos relatórios técnico-científicos foram desenvolvidos com a anuência dos representantes das comunidades. Os resultados mostram uma rede conectando as ações de mulheres da Ciência e de 34 comunidades rurais. Essa rede foi identificada em dez municípios do Estado de Mato Grosso do Sul, principalmente na região conhecida como Corredor do Extrativismo (conexão Cerrado/Pantanal). As mulheres têm trabalhado em projetos pioneiros de extração e comercialização de frutos nativos. Apesar das dificuldades, como a sobreposição ao trabalho doméstico, essas se estruturam e cooperam a partir das demandas locais. Elas se organizam em associações, cooperativas, redes ou projetos para tomar decisões, dar e receber treinamento e enfrentar o desafio de participar de feiras e outros eventos.

PALAVRAS-CHAVE: Comércio justo, Cooperação, Extrativismo, Infraestrutura produtiva, Produção científica.

\begin{abstract}
The aim of this work was to discuss the action of women in the production of food from native plants and the role of networks connecting them in Mato Grosso do Sul State. As specific objectives, we sought to identify and analyze: the history of projects on this theme; the demands that arose in the extractive communities; the strategies involving the creation and strengthening of the network that connects women and their knowledge; the main challenges to the construction of the network; and the importance of women in relation to the topics covered. The data were obtained through document analysis, with consultation to technical-scientific reports (and websites) of extension projects, and research produced by the Federal University of Mato Grosso do Sul and NGOs. The research was
\end{abstract}


developed from participant observation and participatory mapping in rural and urban communities. All projects (research or extension) that resulted in technical-scientific reports were developed with the consent by the representatives of the communities. The results show a network connecting the actions of women from Science and from 34 rural communities. This network was identified in ten municipalities of Mato Grosso do Sul State, especially in the region known as Extractivism Corridor (Cerrado/Pantanal connection). The women have been working in pioneer projects dedicated to extracting and selling native fruits. Despite the difficulties, such as overlapping to domestic work, women are structured and cooperate based on local demands. They organize themselves in associations, cooperatives, networks, or projects to make decisions, give and receive training, and to face the challenge of participating in fairs and other events.

KEYWORDS: Fair trade, Cooperation, Extractivism, Productive infrastructure, Scientific production.

\section{INTRODUÇÃO}

As redes representam conjuntos de atores da sociedade (pessoas ou instituições) que atuam num determinado cenário representado pelos fluxos e das relações estabelecidas. Como conceito, as redes têm sido propícias à teorização de fenômenos e processos como a globalização e os meios digitais (Internet), dentre outros (LOON, 2006). Trabalhos em diferentes áreas têm destacado sua importância na conexão de mulheres (KIMURA et al., 2010; ANBACHA e KJOSAVIK, 2018, AGRÍCOLA, 2019) e fortalecem sua participação em todas as atividades da sociedade, especialmente em países com dados de grande desigualdade de gêneros. Kimura et al. (2010), por exemplo, discutem a formação de uma rede de mulheres ligadas à Ciência, no Japão, onde há um reduzido número de mulheres ocupando cargos e posições de liderança. Estudos que discutem estratégias adotadas na formação das redes são altamente relevantes, porque trazem à tona dados para reflexão e tomadas de decisão, no sentido de mitigar ou propor alternativas.

No Brasil, em alguns campos de pesquisa, as mulheres têm obtido lugares de destaque. Os dados apresentados por Ricoldi e Artes (2016) apontam para uma inserção importante das mulheres em carreiras predominantemente masculinas, mas há muitos desafios. Ainda há prevalência masculina nas Ciências Exatas e da Terra, Engenharias e Agrárias e diferenças de gênero a favor dos homens no recebimento de bolsas produtividade na academia (BARROS; MOURÃO, 2020). Silva et al. (2019) analisaram a representatividade das mulheres em publicações etnobiológicas no contexto brasileiro e observaram não haver diferenças no número de publicações lideradas por homens e mulheres, entretanto há mais artigos em que o autor sênior é do sexo masculino e estes tendem a ser publicados em periódicos de maior impacto. A maioria das mulheres entrevistadas relataram sentir-se discriminadas no meio acadêmico, com desvantagens na coleta de dados por serem mulheres, e testemunharam casos de sexismo nas comunidades estudadas. 
Da mesma forma que as Cientistas, as mulheres que trabalham no campo e na cidade, seja em seus lares ou fora deles, enfrentam desafios diários, considerando a desigualdade de gênero. Schaaf (2003) analisou um movimento de mulheres agricultoras no Rio Grande do Sul iniciado a partir da década de 1980, em que tiveram um papel de destaque por meio de vários tipos de organizações, articulados pelos movimentos feministas, pela Igreja Católica e sindicatos. Como resultado desse trabalho, a categoria das trabalhadoras rurais obteve representação política e ganhou visibilidade na arena pública (SCHAAF, 2003). Essa mobilização e organização em coletivos é relevante, uma vez que, com pouca participação, as mulheres têm menor acesso a cargos, informações e destaque na sociedade (SALES, 2007; STAMARSKI e SON HING, 2015).

Esses estudos são alguns exemplos das várias frentes que desafiam os pesquisadores e os tomadores de decisões nas últimas décadas a compreender a participação da mulher na sociedade, e a definir estratégias para a redução das desigualdades no campo e na cidade, na academia e no poder político. Dentre eles, está a dificuldade de reconhecimento das mulheres como produtoras de alimentos e como sua exclusão das políticas de desenvolvimento rural implica na perda de conhecimentos sobre o manejo da biodiversidade (SILIPRANDI, 2004). Discutir a participação da mulher no processo de produção de alimentos, seus saberes e suas estratégias de articulação permitem avançar na agenda 2030 para o desenvolvimento sustentável (PNUD, 2015), destacando a equidade de gênero, o combate à pobreza e a inclusão social.

Em Mato Grosso do Sul, há um movimento crescente que envolve vários atores da sociedade preocupados com um maior aproveitamento das plantas alimentícias nativas e a participação das mulheres nesse processo começa a ser discutida (ZIOLKOWSKI, 2019; LIBERATO et al., 2019; LEAL et al., 2020). Incentivadas por projetos de organizações governamentais e ONGs, diversas comunidades tradicionais, não tradicionais e indígenas têm se envolvido em cadeias produtivas relacionadas ao aproveitamento das plantas alimentícias, que, conectadas numa rede de conhecimentos, têm tido um papel fundamental para valorização da diversidade biocultural (BORTOLOTTO et al., 2017). Fazer o registro histórico da participação feminina nessa trajetória, incluindo tanto as organizações governamentais quanto as não governamentais em conjunto com as comunidades, permite refletir sobre o processo em curso e sobre as mudanças ocorridas que promovem a valorização de alimentos oriundos da biodiversidade. As mulheres apresentam forte conexão entre o passado e o futuro relacionando a continuidade entre o ser humano e a natureza, sendo 
consideradas guardiãs da terra e da riqueza comunal, principalmente na preservação e transmissão do conhecimento tradicional (FEDERICI e VALIO, 2020).

Ocupando posição central na América do Sul, o estado de Mato Grosso do Sul tem uma posição estratégica onde se conectam plantas e povos muito diversos com 294 espécies de plantas alimentícias potencialmente úteis para a dieta humana (BORTOLOTTO et al., 2018). O Estado possui a segunda maior população indígena do Brasil (CHAMORRO e COMBÉS, 2015) e várias comunidades tradicionais. Somente no Pantanal, incluindo Mato Grosso e Mato Grosso do Sul, na Bacia do Alto Paraguai (BAP), Silva (2020) identificou 10 etnias indígenas. A ECOA (ONG Ecologia e Ação) desenvolveu um mapa interativo com a localização de 50 comunidades tradicionais na BAP (ECOA, 2018). Os povos tradicionais que dependem dos recursos naturais têm um conjunto de saberes e práticas que contribui para a conservação da biodiversidade (DIEGUES, 2019; AMSALU et al., 2018). Há ainda, populações humanas que vivem em assentamentos rurais, propriedades adquiridas pelos governos para serem distribuídas a trabalhadores rurais sem terra, que buscam alternativas de sustentabilidade (CANDIL et al., 2007).

Mesmo com essa rica diversidade biocultural, o extrativismo de frutos, castanhas e outras partes de plantas alimentícias nativas no Estado, era predominantemente para autoconsumo até o final do século XX. Um relatório produzido pela ECOA (ECOA, 1994) mostrou espécies medicinais, alimentícias e para artesanato em diversos municípios do Estado, comercializadas apenas em feiras e com baixíssima intensidade. Essa situação vem mudando nas duas últimas décadas. O extrativismo de cumbaru (Dipteryx alata Vogel) desenvolvido em projetos de assentamentos rurais da reforma agrária com apoio de projetos sustentáveis (CANDIL et al., 2007) tem aumentado a produção de alimentos a partir de plantas nativas do Cerrado.

Desta forma, o objetivo deste trabalho é discutir a atuação das mulheres em sistemas produtivos no estado de Mato Grosso do Sul para garantir a produção de alimentos de forma justa e sustentável e o papel das redes para conectá-las. O estudo visa identificar e analisar: o histórico de projetos socioambientais relacionados ao aproveitamento de plantas alimentícias nativas em Mato Grosso do Sul, as demandas surgidas nas comunidades extrativistas, as estratégias de ação envolvendo a criação e fortalecimento da rede que conecta as mulheres e seus saberes, os principais desafios na construção da rede e a importância da mulher frente aos temas abordados. 


\section{MATERIAL E METODOS}

Este trabalho foi desenvolvido com dados obtidos de projetos socioambientais coordenados pelas autoras que atuam em organizações governamentais e da sociedade civil em Mato Grosso do Sul (MS). Os projetos envolvem atividades de pesquisa e extensão relacionadas ao uso e conservação de plantas alimentícias nativas em comunidades rurais e urbanas do Estado, especialmente nos Biomas do Cerrado e Pantanal (Figura 1). Os dados foram obtidos a partir de consulta aos relatórios técnico-científicos desses projetos mediante a observação participante (GEERTZ, 2008) e mapeamento de campo (GEILFUS, 2002; SOGLIO et al., 2007), entre o período de 2000 a 2020. Todos os projetos que resultaram nos relatórios técnico-científicos consultados foram desenvolvidos com a anuência dos representantes das comunidades. Não se mencionou dados que identificam mulheres ou que expõem seu cotidiano.

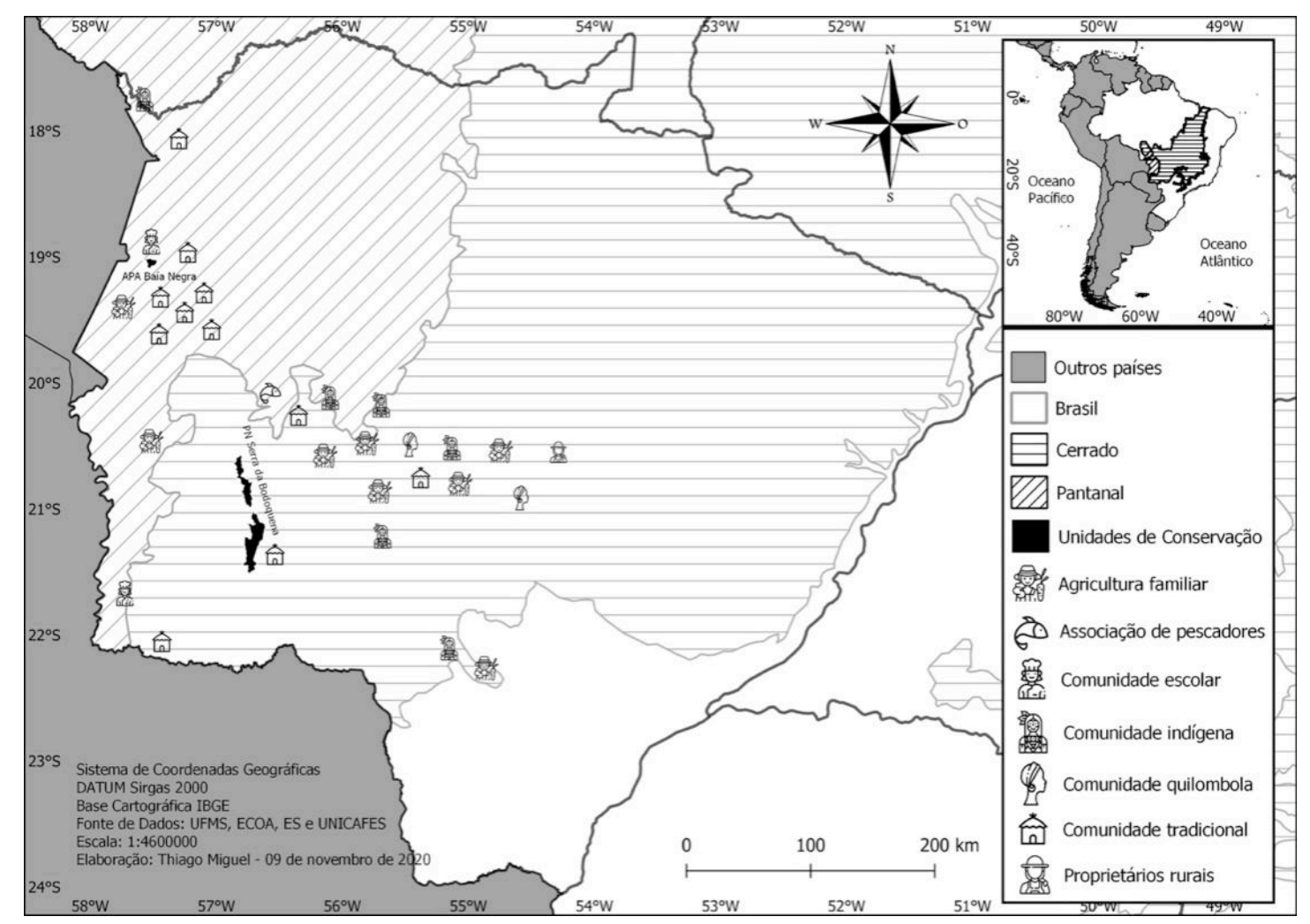

Figura 1: Localização das comunidades que participaram de atividades extrativistas para produção de alimentos a partir de plantas nativas em Mato Grosso do Sul, Brasil.

Foram também usadas informações disponíveis nos sites do Programa "Valorização de Plantas Alimentícias do Pantanal e Cerrado" Programa Sabores (SABORES DO CERRADO E PANTANAL, 2020), da ECOA (ECOA, 2020), da Economia Solidária/UNICAFES - União 
das Cooperativas da Agricultura Familiar e Economia Solidária (UNICAFES, 2020) e do Fórum Brasileiro de Economia Solidária (FBES, 2020). Trata-se de uma abordagem qualitativa para obtenção e análise de dados sobre as relações sociais (MINAYO, 1998), dando maior ênfase ao processo e não apenas aos resultados. A estrutura da rede (as conexões que os atores podem estabelecer) foi elaborada e analisada com base nas informações disponíveis nos projetos socioambientais que envolvem mulheres articuladas em rede para produzir alimentos com base na cultura, nos saberes e na biodiversidade local e nos conhecimentos científicos.

\section{RESULTADOS}

Projetos e programas socioambientais coordenados por membros de organizações governamentais e ONGs (Tabela 1) e articuladoras de grupos sociais de pequenas/os agricultores constituem uma rede (Figura 2) que integra mulheres de 34 comunidades rurais em dez municípios do MS. Esses projetos, desenvolvidos entre os anos 2000 e 2020, visam o aproveitamento sustentável das plantas alimentícias nativas do Cerrado e Pantanal, em especial no Corredor do Extrativismo na conexão Cerrado/Pantanal. O que se busca nesta ação em rede é possibilitar processos contínuos que articulam projetos, pessoas e comunidades, que constroem e possibilitam a existências das redes informais nos seus territórios.

As comunidades indígenas, quilombolas, tradicionais ou da agricultura familiar (como de projetos de Assentamentos da Reforma Agrária) incluídas neste trabalho são representadas por mulheres que se organizam, se reconhecem e se conectam. A "Rede de Mulheres do Cerrado e Pantanal" (CerraPan), articulada por projetos da ONG ECOA - Ecologia e Ação (ECOA, 2020) é uma delas, e é composta por várias comunidades que atuam em atividades extrativistas de frutos, castanhas ou outras partes de plantas para fins alimentícios. Além da ECOA, apresentamos outros dois nós de articulação de projetos associados à Economia Solidária e União Nacional das Cooperativas da Agricultura Familiar e Economia Solidária (ES/UNICAFES) e Universidade Federal de Mato Grosso do Sul (UFMS), cujas principais informações estão apresentadas na Tabela 1 . 
BORTOLOTTO I, M. et al. Mulheres em rede: conectando saberes sobre plantas alimentícias do cerrado e do pantanal. Ethnoscientia, v.6, n.2, especial, 2021. D.O.I.: 10.22276/ethnoscientia.v6i2.387

Tabela 1: Organizações que agregam mulheres em rede, atividades das organizações articuladas em rede, atividades desenvolvidas pelas mulheres, comunidades (participantes) e agências financiadoras $(\mathrm{N})=$ nacional; (I) = internacional. UFMS: Universidade Federal de Mato Grosso do Sul; ECOA: Ecologia e Ação, UNICAFES: União de Cooperativas da Agricultura Familiar e Economia Solidária.

\begin{tabular}{|c|c|c|c|}
\hline Organizacões & UFMS & ECOA & ES/UNICAFES \\
\hline Tipo & $\begin{array}{l}\text { Organização } \\
\text { governamental }\end{array}$ & $\begin{array}{l}\text { Organização Não- } \\
\text { Governamental }\end{array}$ & $\begin{array}{l}\text { Organização Não- } \\
\text { Governamental }\end{array}$ \\
\hline Ações & $\begin{array}{l}\text { Desenvolve pesquisa, } \\
\text { extensão e/ou Ensino e } \\
\text { Inovação. }\end{array}$ & $\begin{array}{l}\text { Desenvolve pesquisa e projetos } \\
\text { socioambientais. }\end{array}$ & $\begin{array}{l}\text { Desenvolve programas de } \\
\text { educação cooperativismo } \\
\text { projetos e pesquisas, } \\
\text { socioambientais. }\end{array}$ \\
\hline $\begin{array}{l}\text { Atividades das } \\
\text { organizações } \\
\text { articuladas em } \\
\text { rede }\end{array}$ & $\begin{array}{l}\text { Coordena e desenvolve } \\
\text { projetos e programas } \\
\text { como o Programa } \\
\text { "Sabores" e outros. }\end{array}$ & $\begin{array}{l}\text { Secretaria e coordena projetos } \\
\text { de fortalecimento junto à } \\
\text { CerraPan. Além de outras } \\
\text { Redes de Organizações, como } \\
\text { a Rede Pantanal. }\end{array}$ & $\begin{array}{l}\text { Coordena projetos, } \\
\text { desenvolve programas de } \\
\text { educação do cooperativismo. }\end{array}$ \\
\hline $\begin{array}{l}\text { Atividades } \\
\text { desenvolvidas pelas } \\
\text { mulheres }\end{array}$ & $\begin{array}{l}\text { Coordena, elabora e } \\
\text { executa projetos de } \\
\text { ensino, pesquisa e } \\
\text { extensão (inclusive cursos } \\
\text { e eventos), orienta e } \\
\text { executa. }\end{array}$ & $\begin{array}{l}\text { Coordena, elabora e executa } \\
\text { projetos, coordena, articula e } \\
\text { mobiliza redes e ações nas } \\
\text { comunidades, desenvolve } \\
\text { pesquisas. }\end{array}$ & $\begin{array}{l}\text { Coordena, elabora e executa } \\
\text { projetos e programas; } \\
\text { coordena, articula ações e } \\
\text { mobilização nas } \\
\text { comunidades; desenvolve } \\
\text { pesquisas, promove cursos, } \\
\text { eventos, feiras e outros. }\end{array}$ \\
\hline $\begin{array}{l}\text { Comunidades } \\
\text { (participantes) }\end{array}$ & $\begin{array}{l}\text { Rurais e urbanas (indígenas, } \\
\text { tradicionais e não } \\
\text { tradicionais) e escolas }\end{array}$ & Rurais (tradicionais e locais) & $\begin{array}{l}\text { Rurais e urbanas } \\
\text { (indígenas) }\end{array}$ \\
\hline $\begin{array}{l}\text { Agências } \\
\text { financiadoras* }\end{array}$ & (N) CNPq, MEC e UFMS & $\begin{array}{l}\text { (I) CEPF, Charles Stewart } \\
\text { Mott Foundation }\end{array}$ & $\begin{array}{l}\text { (N) SESCOOP, FUNBIO, } \\
\text { FBB, BNDES; (I) ONU - } \\
\text { Mulheres }\end{array}$ \\
\hline
\end{tabular}

\footnotetext{
*Agências financiadoras: Conselho Nacional de Desenvolvimento Científico e Tecnológico (CNPq); Ministério da Educação (MEC); União Europeia, Fundo de Parceria para Ecossistemas Críticos (CEPF, na sigla em inglês para Critical Ecosystem Partnership Fund); Charles Stewart Mott Foundation; Serviço Nacional de aprendizagem do Cooperativismo (SESCOOP), Fundo Brasileiro para a Biodiversidade (FUNBIO), Fundação Banco do Brasil (FBB) e Banco Nacional de Desenvolvimento Econômico e Social (BNDES); (I) Organização das Nações Unidas - Mulheres (ONU - Mulheres).
} 


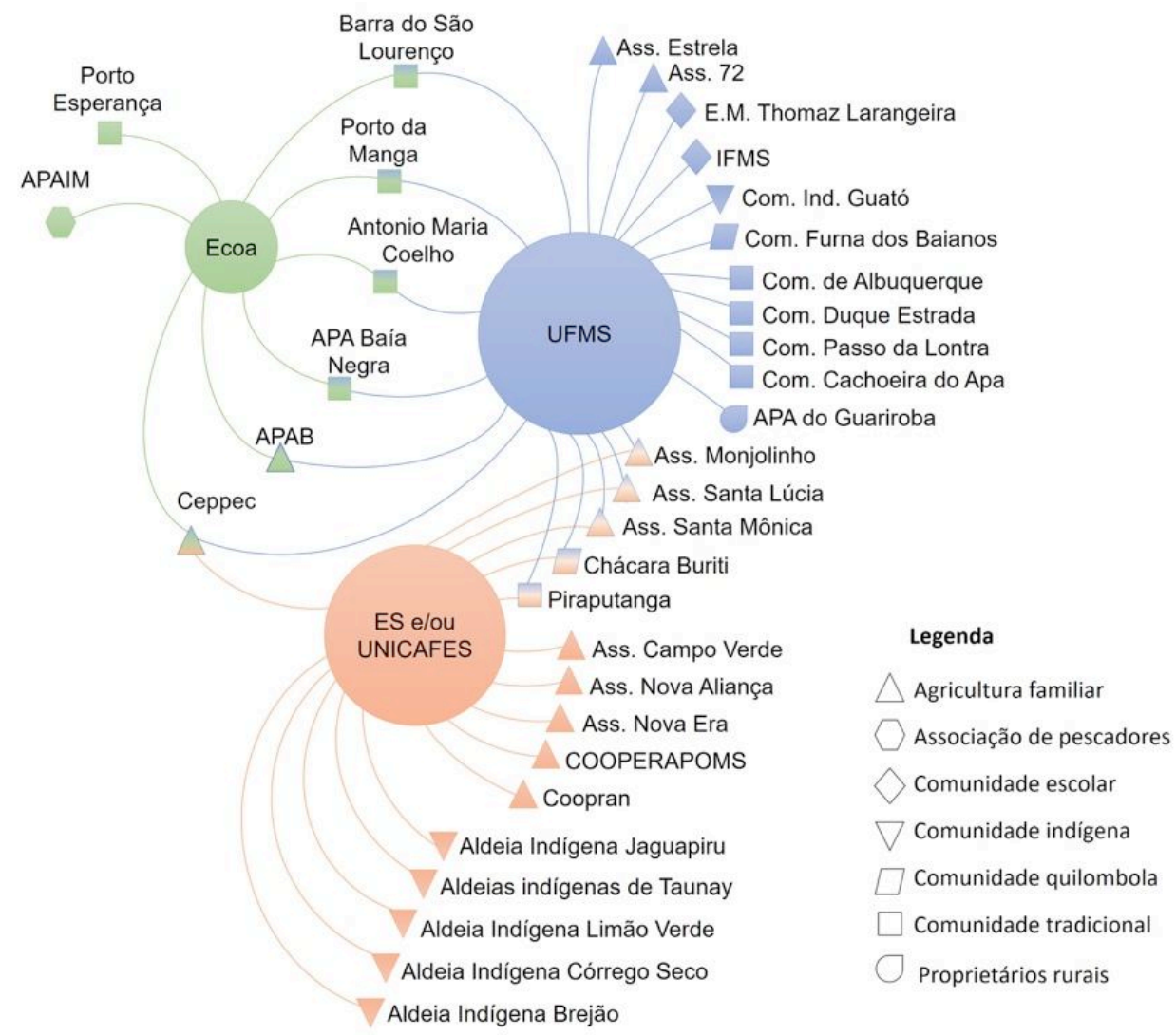

Figura 2: Comunidades rurais e urbanas conectadas numa rede nas quais mulheres atuam em projetos e/ou programas associados à melhoria da qualidade de vida dos moradores e à conservação e valorização de plantas alimentícias nativas do Cerrado e Pantanal em Mato Grosso do Sul, Brasil. APAIM (Associação de Pescadores Artesanais de Iscas de Miranda), APAB (Associação de Produtores Assentamento Bandeirantes), Projeto de Assentamento (Ass.), IFMS (Instituto Federal de Mato Grosso do Sul), Comunidade (Com.), Coopran (Cooperativa dos Produtores Rurais da Região do Pulador de Anastácio), COOPERAPOMS (Cooperativa de Produção e Comercialização da Rede dos Produtores Orgânicos de Mato Grosso do Sul).

Essas organizações possuem mulheres atuantes em projetos de pesquisa e extensão nas comunidades rurais e urbanas do Cerrado e Pantanal no MS desde sua elaboração, execução e coordenação. Muitas das atividades desenvolvidas pelas mulheres das organizações relacionadas na Tabela 1 são semelhantes às desenvolvidas pelas mulheres das comunidades. As mulheres das comunidades atuam como parceiras, sugerindo temas, orientando sobre demandas e participando ativamente da elaboração, desenvolvimento e avaliação até a participação na fase de divulgação dos resultados por meio de palestras, vídeos e debates. Os projetos têm financiamentos diversos, tanto nacionais quanto internacionais (Tabela 1), e dependem de uma agenda que inclui prestações de contas por meio de relatórios técnicoscientíficos periódicos, com dados comprobatórios das ações desenvolvidas. Na rede construída aqui (Figura 2), se indicou as relações entre as comunidades e as instituições proponentes e ou coordenadoras, sem apontar, contudo, as conexões entre as comunidades. É importante registrar que, em muitos casos, foi observada a conexão entre elas, envolvendo 
participação coletiva em eventos, feiras e oficinas, especialmente nas comunidades próximas geograficamente.

\subsection{Breve histórico dos projetos/organizações articuladores da rede}

O Programa de Extensão "Valorização de Plantas Alimentícias do Pantanal e Cerrado" (SABORES DO CERRADO E PANTANAL, 2020), conhecido como "Programa Sabores" inclui segmentos da UFMS (Tabela 1) como institutos, faculdades, escolas além de dois campi localizados no interior do Estado (Corumbá e Aquidauana) e parceiros que atuam de forma conjunta em municípios e comunidades diversas. Estudantes de cerca de 10 cursos de Graduação e quatro de Pós-Graduação, docentes e técnicos de laboratório compõem a equipe desde 2006. A UFMS foi criada em 1962, tem sede na capital, Campo Grande, e campus em nove municípios do Estado.

O Programa Sabores é desenvolvido para sensibilizar a comunidade escolar e a nãoescolar das comunidades rurais e urbanas e inclui professores, alunos e merendeiras. As atividades consistem em oficinas de identificação de plantas alimentícias disponíveis no território, incentivo à coleta de frutos e à produção de alimentos. As orientações versam sobre boas práticas de colheita e pós-colheita, boas práticas de higiene, padronização de receitas, produção de mudas, restauração de áreas degradadas, conservação de polinizadores, estímulo à oferta de pratos em hotéis e restaurantes, desenvolvimento de cursos, oficinas e simpósios. São pesquisados o valor nutricional de frutos, pratos, colheita e pós-colheitas, desenvolvimento de receitas, produção de rótulos, livros, cartilhas, cartões postais e outros. Dentre as espécies incentivadas para colheita (consumo e comercialização) estão: arroz-dopantanal (Oryza latifolia Desv. e Oryza glumaepatula Steud.), laranjinha-de-pacú (Pouteria glomerata (Miq.) Radlk.), acuri (Attalea phalerata Mart. ex Spreng.) e bocaiuva Acrocomia totai Mart. e Acrocomia aculeata (Jacq.) Lodd. ex Mart. (BORTOLOTTO et al., 2017).

A coordenação é desempenhada por um/a docente, e pode mudar, conforme as demandas do Programa. A coordenação faz os contatos prévios com as comunidades e escolas, agenda atividades e articula as ações a serem desenvolvidas. $\mathrm{O}$ curso anual de plantas alimentícias tem um/a coordenador/a a cada ano, que é responsável pela oferta dos cursos e divulgação e relatório. Todas as dez versões do curso de Plantas Alimentícias (de 2011 a 2020) foram coordenadas por mulheres. Dentre as 6 atividades propostas para 2020 e 2021, 5 são coordenadas por mulheres. Os resultados com envolvimento de alunos (bolsistas ou voluntários) dos cursos de Graduação são apresentados em um evento anual chamado ENEX 
(Encontro de Extensão da UFMS) e INTEGRA, com apresentação de trabalhos e publicação de resumos.

A CerraPan foi consolidada e articulada pela ONG ECOA (Ecologia e Ação) (Tabela 1) e ambas continuam conectadas com projetos socioambientais (Figura 2). Constituída a partir de reuniões/assembleias registradas em relatórios técnicos e atas, ocorridas desde o ano de 2015, com o objetivo de fortalecer a articulação coletiva de mulheres que trabalham com os produtos da sociobiodiversidade e processos de manejos artesanais e sustentáveis. A CerraPan representa um conjunto de 43 mulheres que estão organizadas social e politicamente em seus territórios e para além deles, em uma articulação em Rede com representação feminina de oito comunidades tradicionais e locais diferentes, do Cerrado e do Pantanal SulMato-Grossense (ZIOLKOWSKI, 2019; ECOA, 2020). Seus familiares participam diretamente de atividades das comunidades, como Associações de Moradores, Associação de Mulheres e/ou Centros de Processamento Agroextrativistas (ECOA, 2020). No entanto, a Rede de Mulheres é um espaço que se destina somente a elas, tanto nas instâncias deliberativas quanto na própria estrutura organizacional. Essa estrutura envolve uma coordenação de três mulheres e uma representante de cada comunidade, responsável pela interlocução dos assuntos da "Rede" com as demais mulheres na comunidade, e uma secretaria executiva, hoje representada pela organização Ecoa.

Já a ECOA foi criada em 1989 na capital, Campo Grande, por um grupo de pesquisadores que incluía biólogos, jornalistas, engenheiros, educadores e outros. O principal objetivo da ONG é estabelecer um espaço para projetos, reflexão, debates e políticas públicas para a conservação ambiental e a sustentabilidade (ECOA, 2020).

A União Nacional das Cooperativas da Agricultura Familiar e Economia Solidária (UNICAFES) e a Economia Solidária (ES) (Tabela 1), desenvolvem ações muito mais amplas do que está representado na Figura 2. Neste trabalho, indicamos apenas as associações, grupos, cooperativas e outros do MS que possuem mulheres que trabalham com plantas alimentícias da sociobiodiversidade, com relação de trabalho (ações de projetos) com as instituições aqui analisadas. Muitos dos empreendimentos/grupos com os quais a UFMS e Ecoa atuam têm também o perfil de ES e, consequentemente, fazem parte da Rede ES. Da mesma forma, cada grupo, associação ou mesmo cada mulher tem contato com outros grupos ampliando as conexões da rede apresentadas neste trabalho.

A UNICAFES é uma organização de abrangência nacional, com sede em Brasília DF e está presente em 20 estados (UNICAFES, 2020). O MS tem uma UNICAFES que atua 
de forma integrada em parceria com a Central dos Trabalhadores/as da Economia Solidária (CTES). A ES é um movimento que congrega um conjunto de atividades sociais, econômicas e culturais, centradas no ser humano, caracterizado pela igualdade e a justiça, e os empreendimentos solidários que se organizam no formato de autogestão (FBES, 2020; BRASIL, 2013). Atuam no fortalecimento das cooperativas da agricultura familiar e economia solidária. A UNICAFES realiza desde 2018 o Programa de Educação do Cooperativismo Solidário - PECSOL.

A Rede da Economia Solidária se desenha no MS através da experiência prática de trabalhadoras e trabalhadores, que pelo trabalho coletivo e associado, tece novas concepções de trabalho e relações econômicas, ambientais, culturais e sociais; abrindo um campo de diálogo político e de formação. Segundo o mapeamento de Economia Solidária, realizado pelo Sistema de Informação em Economia Solidária (SIES) da Secretária Nacional de Economia Solidária (SENAES) 2011-2012 (BRASIL, 2013), foram cadastrados no MS 294 empreendimentos solidários, distribuídos em 41 municípios perfazendo um total de 9.554 pessoas, sendo 5.669 mulheres e 3.885 homens.

Dentre as atividades associadas ao Movimento de Economia Solidária no MS, destacamos as de valorização, manejo e pesquisa com os frutos nativos do Cerrado no assentamento Andalúcia, município de Nioaque/MS, iniciado em 2000, com um primeiro projeto: "Produção sustentável e capacitação no assentamento Andalúcia". Esse projeto foi possivelmente o primeiro nessa linha no MS, realizado pela ECOA, com apoio do programa de Pequenos Projetos Ecossociais (PPP-Ecos). O projeto passou a fazer parte da vida das pessoas do assentamento, mas principalmente das mulheres.

Em 2002 foi realizado no mesmo assentamento, o primeiro mapeamento e levantamento de três espécies-chave para as comunidades, com objetivo de conhecer a população, distribuição e o quantitativo do cumbaru (D. alata Vogel), pequi (Caryocar brasiliense Cambess) e jatobá (Hymenaea stigonocarpa Mart. ex Hayne). Atualmente, além de H. stigonocarpa, foram identificadas também Hymenaea courbaril L. e Hymenaea martiana Haynee. Uma das estratégias resultante dessas ações foi a instituição do Corredor do Extrativismo, que é um instrumento de caráter social, ambiental e econômico, desenvolvido com objetivo de fortalecer uma atuação em Rede dos agricultores familiares, extrativistas, indígenas, quilombolas e empreendimentos econômicos solidários.

Em 2008, foi constituída a CTES, que nasceu com o propósito de fortalecer a Central de Comercialização da Economia Solidária (CCES), através da articulação dos 
Empreendimentos Econômicos Solidários (EES) organizados em rede, fomentando a prática da autogestão, comércio justo e solidário e consumo consciente, possibilitando a geração de renda para centenas de mulheres. A CCES é o espaço de comercialização da economia solidária que congrega os EES que formam a Rede da Economia Solidária.

Em 2009, um segundo projeto denominado "Gestão em Rede" foi realizado pelo CEPPEC (Centro de Produção, Pesquisa e Capacitação do Cerrado) (Figura 2), organização social dentro do Projeto de Assentamento Andalúcia. O CEPPEC contou com a parceria da ONG Casa Verde (de Brasília - DF). Esse projeto envolveu tanto grupos rurais quanto urbanos, buscando somar os aspectos da produção com ações de comercialização e logística. Nesse mesmo ano, o Instituto Marista de Solidariedade (extinto em 2017), executor do Projeto Nacional de Comercialização Solidária em parceria com a Secretaria Nacional de Economia Solidária (SENAES), somou-se às ações do Corredor do Extrativismo. Nos anos de 2013 a 2015, foi realizado o projeto Estruturação da Cadeia Produtiva do Pequi, pelo Instituto Marista de Solidariedade. Foi um conjunto de ações que potencializou e deu visibilidade à proposta do Corredor do Extrativismo, um projeto que fortaleceu os EES formados majoritariamente por mulheres, proporcionou ações de pesquisa (monografias), estruturação física das agroindústrias com aquisição de equipamentos, possibilitou a criação de identidade visual e logomarca desses empreendimentos.

A Central dos Trabalhadores da Economia Solidária (CTES) está realizando o projeto "Fortalecimento dos Empreendimentos Solidários das Mulheres do MS" (dezembro de 2019 a março de 2021), com apoio da Fundação Banco do Brasil e ONU Mulheres (Tabela 1). Um dos objetivos do projeto é empoderar mulheres agricultoras nos seus espaços de atuação, para o fortalecimento da rede de economia solidária. É um projeto com foco na estruturação dos empreendimentos solidários das mulheres, com um forte debate sobre violência e direitos da mulher.

\subsection{A atuação em rede e as demandas dos projetos relacionadas à mulher}

Como resultado das ações de extensão do Programa Sabores, surgiram novas perguntas sobre as plantas alimentícias nativas e formas de uso e manejo que, muitas vezes, se tornam alvo de ações de pesquisa ou novas ações de extensão. O grupo de pesquisa da área de Tecnologia de Alimentos da UFMS é constituído em sua maioria por mulheres e tem publicado trabalhos sobre processamento de frutos nativos das mais diversas espécies. Envolvem a caracterização da ação antimicrobiana de frutos (SANTOS et al., 2017), o 
fornecimento de alimentos com maior vida útil e agregação de valor como farinha de casca de pequi (C. brasiliense) (CAMPOS et al., 2016), geleias de bocaiuva (A. aculeata) (SILVA et al., 2018; SOUZA et al., 2019), de canjiqueira (Byrsonima cydoniifolia A. Juss) (PRATES et al., 2017), doce cristalizado de bocaiuva (Acrocomia spp.) (DONADON et al., 2017), frozen yogurt de guavira (Campomanesia spp.) (SILVA et al., 2018) e de laranjinha-de-pacu ( $P$. glometara) (NOGUEIRA et al., 2018), biscoito de caraguatá integral (Bromelia balansae Mez) (FIORAVANTE et al., 2016), cookie de cumbaru (D. alata) (SANTOS et al., 2018 a), bebida hidrossolúvel de cumbaru (D. alata) (FIORAVANTE et al., 2017) e armazenamento de amêndoas torradas de baru (FERNANDES et al., 2020), além da conservação pós-colheita de canjiqueira (B. cydoniifolia) (PRATES et al., 2015), de guavira (Campomanesia spp.) (CAMPOS et al., 2012), suplemento proteico de amêndoa de bacuri (A. phalerata) (RAMOS et al., 2017; SANCHES et al., 2020), estabilidade de óleo de babaçu (Attalea speciosa Mart. ex Spreng.) (MELO et al., 2019) e o efeito benéfico de espécies de guavira (Campomanesia adamantium Cambess.) (CARDOZO et al., 2018; NASCIMENTO et al., 2017), de jatobá (H. stigonocarpa) (ARAKAKI et al., 2016), e proteína de arroz-do-pantanal (O. latifolia) para saúde (BARBOSA et al., 2017).

Da mesma forma, um conjunto de trabalhos liderados por mulheres da área de botânica associadas ao Programa Sabores têm resultados recentes nessa área, como o estudo sobre a coleta e identificação de plantas alimentícias no MS (BORTOLOTTO et al., 2018), etnobotânica, (BORTOLOTTO et al., 2015; BORTOLOTTO et al., 2019; SELEME et al., 2020), rede de conhecimentos com diversos atores (BORTOLOTTO et al., 2017) e restauração ecológica com uso de guavira (C. adamantium) (GONDIM et al., 2020). Estudos com dados fenológicos e de polinização trazem informações relevantes para a área de conservação de algarobo (Prosopis rubriflora Hassler) (SIGRIST et al., 2018), do Chaco brasileiro, assim como os dados para fenologia de O. latifolia (BERTAZZONI e DAMASCENO-JÚNIOR, 2011).

Nas comunidades alvo do Programa, onde as mulheres são as principais interlocutoras, elas têm buscado informações nutricionais de frutos e de produtos, informações sobre embalagens, rótulos com valor nutricional, receitas, informações sobre boas práticas de higiene e armazenamento de produtos, produção de mudas e sobre o processo de produção de farinhas. Para atender essas demandas, além dos resultados associados à produção científica, soma-se a produção de livro de receitas (DAMASCENO-JÚNIOR et al. 2010) e rótulos com valor nutricional. Como forma de divulgar resultados de pesquisas nas linhas da ação de 
extensão desenvolvida pelo Programa Sabores e dar suporte às atividades a campo, foi criada a "Coleção Saberes do Cerrado e Pantanal", contendo sete volumes (BORTOLOTTO et al., 2017; BRESSAN et al., 2017; DAMASCENO et al., 2017; DONADON e CAMPOS, 2017; DONADON et al., 2020; JUNQUEIRA et al., 2020; SILVA et al., 2017). Dos 26 autores dessa coleção, 21 são mulheres. Em 2018, duas acadêmicas do curso de Jornalismo da UFMS, desenvolveram um projeto de pesquisa sobre o impacto das ações de desenvolvimento de atividades relacionadas aos frutos nativos em comunidades parceiras. Os resultados apontaram para o forte engajamento das mulheres nessas comunidades (BUENO e OLIVEIRA, 2018).

A CerraPan definiu uma agenda interna prioritária, baseada nos diálogos entre as mulheres das comunidades e suas necessidades, que envolve também assuntos de âmbito estadual ou federal. Sua agenda está dividida entre os temas: política, que envolve direitos humanos das mulheres, direitos trabalhistas, infraestrutura e incidência política das mulheres; agenda de produção, que versa sobre auto-organização, questões jurídicas e fiscais para os centros de produção e acesso a mercados, e; agenda de conservação, que dialoga sobre sustentabilidade nas atividades desenvolvidas, além de boas práticas de higiene e manipulação de alimentos. Essas são as demandas prioritárias sobre as quais as mulheres definem suas ações dentro da Rede.

A Rede de ES tem participação cada vez mais ativa das mulheres nas atividades dos projetos, com atuação na rede, na organização e gestão dos empreendimentos, na produção e comercialização. O percentual de mulheres que atuam na CTES e na CCES é de $90 \%$. As mulheres têm buscado informações e capacitação. $O$ projeto "Fortalecimento dos Empreendimentos Solidários das Mulheres Agricultoras no MS”, realizado pela CTES, tem identificado uma série de demandas estabelecidas pelas mulheres nas comunidades (assentamentos e aldeias), entre elas: i) reconhecimento do papel das mulheres na sua comunidade, ii) direito das mulheres, iii) participação nas tomadas de decisão nas suas associações e cooperativas; iv) melhores condições de trabalho; v) promoção e difusão dos seus produtos e serviços. Elas têm demandado, também, acesso adequado à saúde, organização social, gestão, desenvolvimento, agroecologia, mercado, conhecimento e uso das tecnologias da informação. 


\subsection{Criação e fortalecimento de elos que conectam as mulheres e seus saberes}

O Programa Sabores não objetiva a atuação específica de mulheres, mas sua estrutura é composta essencialmente por elas em todas as dimensões acadêmicas (estudantes, técnicos e docentes). Em 2015 e 2016, dos 31 membros do Programa Sabores reunidos em uma única proposta, 21 eram mulheres. Dessas, 17 eram doutoras e atuavam na graduação e pósgraduação nas áreas de Ciências Biológicas, Farmácia, Nutrição, Engenharia de Alimentos e Turismo. Essa grande capacitação das mulheres permite o fortalecimento de projetos de extensão e pesquisa que interagem a comunidade universitária com os territórios, atendendo demandas surgidas.

Nas comunidades, os saberes locais são valorizados e busca-se incentivar o aproveitamento das plantas disponíveis no entorno e que fazem parte da cultura local. Desde o início do Programa, a participação feminina das comunidades nas atividades de extensão propostas, juntamente com os jovens, foi visível, com sua liderança na divulgação das atividades e na responsabilidade de investimento no aproveitamento e conservação de plantas alimentícias nos seus territórios. Para valorizar essa forte atuação das mulheres, elas foram incluídas como palestrantes nas versões dos cursos anuais de plantas alimentícias e no Simpósio sobre Frutos Nativos e Exóticos (SINATEX 2017, 2019). Há também a participação de homens, mas de maneira geral, considerando que as mulheres são as principais parceiras nas comunidades, esse espaço tem sido aberto principalmente a elas.

A CerraPan tem como principais estratégias de ação a mobilização coletiva e a articulação de agendas comuns entre as mulheres. Contudo, há agendas de especificidades territoriais, mas sobre as quais esse grupo de mulheres é sensível e se soma em apoio às demais mulheres da rede. Por exemplo: há duas comunidades, das oito envolvidas na Rede, que sofrem impacto direto de empresas mineradoras atuantes no Pantanal. Essa é uma questão que conecta a luta de todas as mulheres da Rede, fortalecendo seus elos de ação coletiva e os diálogos de compreensão social de seus entornos. Essa rede envolve comunidades dos municípios de Nioaque, Miranda, Ladário e Corumbá e tem como ferramentas de articulação as mídias sociais hoje já acessadas em todas as comunidades, embora algumas com limitação de uso, mas que, se configura, hoje, em uma forma eficaz de contato direto. Além disso, se realizam encontros e reuniões. Os encontros são mais dependentes da captação de recursos, fundamentais (mas não realizados em tempos da Pandemia causada pelo Covid 19) para a conexão entre elas e o intercâmbio de saberes. 
A Rede de Economia Solidária investe na formação e assessoria técnica como estratégia, formação coletiva, construção e partilha de saberes, reflexões e pesquisas sobre e a partir da realidade dos/das trabalhadores/as da rede. A Rede tem uma ampla atuação com projetos que priorizam o fortalecimento das cadeias produtivas, os circuitos curtos e médios de comercialização, o consumo sustentável de produtos da agricultura familiar e economia solidária. No campo da difusão, as estratégias focam nos intercâmbios locais e interestaduais, que favorecem a troca de experiências e do conhecimento; eventos como as feiras da agricultura familiar e economia solidária do local ao nacional; seminários e congressos com apresentação de trabalhos, rodas de conversas e debates sobre os rumos da Rede; uso das mídias sociais e tecnologias da informação; produção de materiais formativos, educativos e de apoio que divulgam e os resultados dessa vivência diária extremamente rica que precisa de visibilidade e apoio de políticas públicas.

\subsection{Os principais desafios para a construção da rede}

A descontinuidade de editais para financiamento de projetos na linha dos projetos e programas desarticula a equipe de trabalho na Universidade, impossibilita a continuidade de ações e afasta a equipe dos territórios. Uma fonte importante de financiamento nessa linha no período de 2011 a 2017 foi do MEC/SESU/PROEXT, que não mais lançou edital nos últimos anos. Esses editais se caracterizavam pela importante articulação com políticas relacionadas à segurança alimentar e nutricional (SAN) e estratégias de uso sustentável da biodiversidade, que pautavam o ensino, pesquisa e extensão, envolvendo de toda a comunidade universitária com a sociedade. $\mathrm{O}$ distanciamento da equipe acadêmica com as comunidades é o principal fator de enfraquecimento de elos, mesmo que resilientes.

Dentre as atividades mais afetadas estão as oficinas com merendeiras em escolas e as oficinas para o desenvolvimento de receitas. Algumas mulheres participam de outras redes e elas próprias se articulam para dar continuidade às ações. Todavia, há outras que se encontram em fase inicial de sensibilização e necessitam de um apoio mais contínuo. Em algumas situações, é difícil manter a atividade desenvolvida pelas mulheres, já que os jovens querem sair das comunidades, ou mesmo não veem a importância da atividade relacionada com as plantas alimentícias com o mesmo olhar. Há ainda alguns desafios a serem enfrentados, como a participação em feiras e eventos fora de suas comunidades, seja em função da distância ou de hábitos culturais que exigem sua permanência junto aos familiares. 
Tanto na CerraPan, como no Programa Sabores, também se enfrenta o desafio dos apoios continuados que mantêm as ações que envolvem encontros, que suportam e impulsionam a comercialização de produtos, financiamentos para aprimorar suas atividades produtivas, que nesta rede são bastante responsáveis pela autonomia social e política das mulheres. As famílias nos territórios envolvidos têm rendimentos médios de um salário mínimo, a partir de levantamentos realizados pela ONG Ecoa. Essa baixa renda inviabiliza a autossuficiência na promoção de ações e encontros coletivos, sobretudo porque exigem o deslocamento para fora das comunidades.

Os grupos de mulheres têm realidades distintas entre seus modos de vida. Algumas sofrem com as más condições das estradas rurais, outras com os altos custos de navegação para chegar à cidade mais próxima. Dessa forma, a mobilidade dessas mulheres, tanto para ações da Rede (CerraPan), quanto para comercialização dos produtos da sociobiodiversidade, constitui um desafio atualmente. Além disso, as queimadas no Cerrado e Pantanal ocorridas em 2019 e 2020 (OBSERVATÓRIO DO PANTANAL, 2020), expõem as comunidades a danos incalculáveis, causado problemas respiratórios e afetando as reservas agroextrativistas, comprometendo seus meios de reprodução. Quatro das oito comunidades que compõem a Rede, localizadas no Pantanal, tiveram impactos diretos nas atividades produtivas das mulheres.

A descontinuidade dos projetos e programas e a falta de recursos humanos e financeiros constituem uma realidade também para a Rede ES. Por ser uma rede informal, os desafios que afetam os empreendimentos das mulheres nas suas localidades potencializam-se na rede. Desafios como a baixa escolaridade das mulheres, pouca qualificação para gestão dos empreendimentos, ausência de organização institucional, ausência de uma consciência associativista/cooperativista, prevalência do machismo, patriarcalismo e individualismo, excesso de trabalho, carência de assistência técnica direcionada, que respeite suas especificidades, dificuldade no acesso a crédito diferenciado, desconhecimento das tecnologias da informação, uso das mídias sociais de forma qualificada, ausência de estrutura logística (transporte, armazenamento e distribuição).

Além disso, de maneira geral, o espaço público nas comunidades tem um alto preço para as mulheres. A família, por construção cultural, entende que a mulher é a única responsável por tudo que se refere aos cuidados do lar. $\mathrm{Na}$ área rural, essa realidade é ainda mais intensa. As mulheres muitas vezes acabam em desvantagem e é um grande desafio sua participação nas atividades, seja em associações, cooperativas ou mesmo grupos informais, no 
trabalho nas agroindústrias, participação nas feiras, quando é o caso. Com isso, o tempo para estudos e lazer é inexistente. Esse conjunto de dificuldades afeta o desenvolvimento e o fortalecimento da rede.

\subsection{A importância da mulher frente aos temas abordados}

A participação das mulheres no Programa Sabores, como abordado nos tópicos anteriores, inclui tanto as mulheres que fazem parte da comunidade Universitária, quanto as mulheres das comunidades, além de todas as parcerias dos diversos projetos. Esses grupos têm papéis e importância bastante diferentes, mas intrinsecamente relacionados, considerando que são complementares. Na Universidade e nas organizações parceiras, as mulheres estão atentas ao desenvolvimento de projetos de pesquisa e extensão que atendam às demandas observadas. Nas comunidades, as mulheres têm se apropriado de seus saberes de forma crescente. Em diversas situações, houve poucas oficinas de sensibilização para incentivar o aproveitamento de plantas alimentícias nativas e a partir daí, as mulheres assumiram as responsabilidades para manter e inovar, desenvolvendo suas próprias receitas, fazendo outras parcerias e fortalecendo sua identidade. Ou seja, tanto na Universidade quanto nas comunidades, as mulheres estão assumindo para si, a responsabilidade de trabalhar com as plantas alimentícias nativas.

Na CerraPan, o papel das mulheres na tomada de decisões em suas comunidades é crescente, sobretudo nas duas últimas décadas conforme os projetos desenvolvidos pela Ecoa puderam mapear e apoiar. O período refere-se à identificação do surgimento de grupos organizados de mulheres nas comunidades. Também há a criação de grupos mistos em que as mulheres também lideram. São associações e centros de pesquisa e produção comunitária, alinhados à sociobiodiversidade local, que demonstram, na prática, a importância dos saberes que elas detêm sobre seus territórios. Isso as coloca em outros espaços de decisão e construção social, para além dos espaços domésticos e do núcleo familiar, ocupando a coordenação desses grupos, liderando a consolidação de trabalhos em Rede e ocupando espaços públicos pela luta de direitos.

Hoje as mulheres da CerraPan se dividem para uma participação política ampliada, como integrantes da Rede Pantanal, uma rede de fortalecimento das alianças entre atores da região da Bacia do Alto Paraguai, no Conselho Nacional dos Povos e Comunidades Tradicionais, no Conselho Gestor da Área de Proteção Ambiental Baía Negra e na CISMu - 
Comissão Intersetorial de Saúde da Mulheres - vinculada ao Conselho de Saúde da Mulher do município de Corumbá. Nestes espaços, suas experiências de vida, em suas comunidades, a compreensão sobre seus territórios e o entendimento sobre o meio-ambiente, fazem total diferença na defesa de seus direitos e pela conservação de plantas alimentícias no Cerrado e Pantanal. As mulheres, em seus territórios, fazem trabalhos diários de conservação dos ecossistemas. Elas conservam as espécies existentes; mantêm manejos sustentáveis de frutos nativos; fazem o adensamento das espécies vegetais nativas, plantando novas sementes e mudas e recuperam nascentes.

A atuação das mulheres nos projetos de ES está relacionada ao conhecimento, uso e manejo das plantas nativas sendo determinante a forma como participam, os meios que possibilitam que as mulheres contribuam com esses processos e com essa transferência de conhecimento de informações oportunizando interação entre o conhecimento científico e o saber local. É nesse ambiente de oportunidades que o aprendizado acontece, que o conhecimento se multiplica e é transmitido. São inúmeras associações, cooperativas, grupos informais e microredes trabalhando e desenvolvendo ações de manejo florestal, mapeamento de espécies frutíferas, coleta de sementes, produção de mudas, desenvolvimento de produtos alimentícios, medicinais e artesanato com uso de fibras e corantes naturais. Tudo a partir das plantas. Outro aspecto dessa relação é a difusão dessa informação, é o tornar público, dar visibilidade, seja pela produção de artigos, revistas, cadernos, manuais, marcas e rótulos.

No projeto "Cadeia Produtiva do Pequi”, que envolveu aldeias indígenas da etnia Terena e projetos de assentamentos da Reforma Agrária, as mulheres foram muito ativas no trabalho de manejo de plantas, na coleta das sementes, na produção e plantio das mudas. O projeto gerou um guia da cadeia do pequi, manual de boas práticas na produção de alimentos e 5.000 mudas de pequi distribuídas para os grupos participantes. É a participação das mulheres na rede que favorece a instituição de estratégias como o Corredor do Extrativismo e o espaço Gosto do Cerrado na Central de Comercialização da Economia Solidária em Campo Grande - MS. Com isso os projetos contribuem para que as mulheres e seu legado no conhecimento das plantas saiam da invisibilidade, mude suas vidas e de suas comunidades.

\subsection{O trabalho com frutos $e$ as atividades com familiares $e$ comunidade}

As mulheres pesquisadoras e atuantes nos projetos de extensão e pesquisa sempre tiveram boa recepção e aceitação das propostas nas comunidades. Por outro lado, em muitas situações, o acúmulo de tarefas, torna-se extenuante. Ir às comunidades implica em se 
deslocar de sua cidade por dois ou mais dias, deixar organizada a casa, o cuidado com os filhos ou demais membros da família, o laboratório, as orientações dos/as alunos/as, as aulas e diversas outras atividades. Os/as bolsistas, estudantes de graduação, orientados/as por essas mulheres pesquisadoras acabam tornando possível as atividades, se deslocando juntamente com as orientadoras e contribuindo com as atividades propostas, mas inclusive eles/as podem estar submetidos/as ao acúmulo de tarefas.

Nas comunidades, essa situação não é diferente. Em muitos casos, o processo de incentivar o aproveitamento de frutos nativos (do mato) implica numa releitura por parte das mulheres desse novo conceito de "fruto" para o mercado. Para compreender esse "novo conceito" dos frutos, as mulheres precisam estudar, analisar e decidir por um novo investimento. Para isso, precisam sair de suas comunidades, participar de feiras, cursos e, muitas vezes, se deparam com a resistência familiar, como já mencionado anteriormente, e com dificuldades semelhantes às das pesquisadoras, ou seja, precisam deixar seu trabalho doméstico, que no retorno, muitas vezes, está por fazer. Felizmente, há outras situações que demonstram o contrário, ou seja, mulheres que seguem com uma rede de apoio, também encontrada pelas mulheres pesquisadoras das diversas organizações que desenvolvem os projetos junto às comunidades.

Em outras situações, as mulheres acumulam essas atividades, como observado na rede de ES. No projeto realizado pela Central dos/as Trabalhadores/as da Economia Solidária (CTES), para o fortalecimento dos Empreendimentos Econômicos Solidários (EES) das mulheres rurais, esse debate está muito presente. Uma tentativa do debate que está sendo promovido é sobre como envolver a família de forma a compartilhar essas responsabilidades, possibilitando assim, que as mulheres não sejam as únicas responsáveis por esse conjunto de atividades e trabalhos, mas sim do coletivo a que elas estão envolvidas. À medida que as mulheres participam e abrem esse diálogo na família e na comunidade, algumas pequenas mudanças emergem. $\mathrm{O}$ fato é que as mulheres se reinventam e se sobrecarregam. $\mathrm{O}$ trabalho com a coleta dos frutos é um trabalho pesado, com pouca infraestrutura de apoio, como veículos e/ou equipamentos que poderiam facilitar e agilizar o processo, trazendo um retorno com menos custoso para as mulheres.

\subsection{A importância de saberes tradicionais e recentes sobre plantas nativas}

O processo que envolve membros da comunidade universitária e das comunidades participantes no "Programa Sabores" está atrelado a um conjunto de ações que incentiva o uso 
de plantas de acordo com os conhecimentos locais, fortalece saberes e práticas que estavam sendo abandonados ou aqueles relacionados a espécies alimentícias que são abundantes e ainda fazem parte de sua cultura. A proposta do Programa de extensão é desenvolver projetos que atuem respeitando os processos internos das comunidades. Nesse sentido, as mulheres são envolvidas em atividades que vão desde a coleta e identificação de plantas até a definição das espécies a trabalhar e na participação em eventos. A CerraPan trabalha baseada nos saberes locais que, alinhados com os estudos desenvolvidos por outras organizações e projetos, como o "Programa Sabores", possibilita o aprimoramento da utilização dos frutos nativos pelas mulheres nas comunidades. A CerraPan tem como objetivos principais reconhecer e destacar os conhecimentos de mulheres sobre seus territórios e ecossistemas, em especial no que se refere ao uso das espécies nativas de produtos florestais não madeireiros. Seus saberes e o manejo de diferentes espécies vegetais são assuntos de diálogo interno desta Rede.

$\mathrm{Na}$ Rede de ES, composta majoritariamente por mulheres do Cerrado e Pantanal, o conhecimento tradicional é um valor indissociável das comunidades e remonta às/os antepassadas/dos. Esse conhecimento passa de geração em geração, mas muito se perde ao longo do tempo. Os projetos desenvolvidos buscam formas de resgatar e registrar esse conhecimento e contribuem para sua perpetuação. Para além do valor cultural, imaterial, esse conhecimento soma esforços e ações na identificação de formas de preservação e conservação das plantas nativas, sejam alimentícias, medicinais, para o artesanato e outras associadas ao uso sustentável, que se conectam aos saberes locais. Esse conhecimento tem contribuído para geração de uma infinidade de produtos, sejam alimentos que promovem a SAN, bem como a pesquisa, construção e difusão do conhecimento os medicinais no cuidado com a saúde e a vida nas comunidades ou na produção de cosméticos e artesanato. As redes contribuem para a valorização e difusão desse conhecimento. Com pesquisas, desenvolvimento de métodos e tecnologias, é possível ampliar esse conhecimento.

\section{DISCUSSÃO}

A rede apresentada neste trabalho conecta mulheres e seus saberes, comunidades locais, diversos segmentos da sociedade (inclusive mercados) e instituições (governamentais e não governamentais). Elas atuam em projetos socioambientais com aproveitamento de plantas alimentícias nativas, especialmente dos frutos nativos, com atividades que vão do extrativismo à sua comercialização no MS. Uma característica do trabalho realizado pelas organizações da sociedade civil, junto às comunidades é seu caráter contínuo e permanente, 
mesmo com a descontinuidade de editais e linhas de financiamento. A atuação crescente da mulher nesse contexto histórico está evidente em todos os setores, tanto na academia quanto fora dela. É possível visualizar o empoderamento das mulheres, com a geração de produtos e serviços associados às plantas alimentícias nativas, autonomia financeira, dinamização da economia local e melhoria da sua vida e de suas famílias. Dentre os resultados no Pantanal, é possível destacar a produção de geleias com a laranjinha-de-pacu ( $P$. glomerata), produção de farinha de acuri (A. phalerata) e da colheita de arroz-do-pantanal (Oryza spp.) onde as mulheres estão à frente (BORTOLOTTO et al., 2017) assim como em relação à produção de farinha de bocaiuva (Acrocomia spp.) (DIAS e GALVANI, 2017). Da mesma forma, no CEPPEC, as mulheres sempre estiveram à frente e elas representam hoje um importante centro de pesquisa e processamento de frutos do Cerrado, especialmente do cumbaru $(D$. alata) (CANDIL et al., 2007). As mulheres representam, em média, 43\% da força de trabalho agrícola nos países em desenvolvimento e o acesso geral das pessoas à alimentação depende, em grande parte, do trabalho das mulheres rurais (FAO, 2011).

Situação semelhante é encontrada em outros países, onde as mulheres têm forte atuação na produção de alimentos, se tornando responsáveis por uma importante etapa das estratégias para garantir a soberania e segurança alimentar e nutricional. Os resultados do estudo de Anbacha e Kjosavik (2018) desenvolvidos na Etiópia mostram uma rede voluntária de apoio social entre amigos, vizinhos e famílias na qual todas as mulheres participam, independentemente das bases de subsistência, status econômico e diferenças de idade. Elas compartilham recursos como itens alimentares, trabalho e dinheiro com base na confiança e na solidariedade com o objetivo principal de superar a escassez de alimentos que aumenta durante a seca. Nessa mesma linha, Bee (2014) analisou os resultados de pesquisas em duas comunidades na região central do México e defendeu que as percepções e estratégias das mulheres para manter a SAN são derivadas de seus contextos sócio-políticos, ambientais e econômicos.

As ações sociais protagonizadas por mulheres na América Latina vêm sendo registradas desde a década de 1970, de forma a focar na coletividade, transformação do trabalho cotidiano, social e reprodutivo, com maior visibilidade nos últimos anos. Defendendo suas origens ancestrais, o feminismo comunitário vai além, com a produção de novas formas de cooperação, divisão de riquezas e solidariedade (FEDERICI e VALIO, 2020). 
Na região Sudoeste do Estado vizinho, Mato Grosso, os recursos financeiros obtidos pelas mulheres dos Projetos de Assentamento (PAs) por meio da atividade extrativista sustentável têm sido essenciais para fortalecer o reconhecimento de sua força de trabalho e a conquista de sua autonomia/cidadania, assim como a contribuição na construção de práticas que visam ao bem-estar da família e das pessoas que vivem no campo (MENDES et al., 2014). Nessas comunidades analisadas, as mulheres adquiriram o direito de participar de associações e cooperativas, abrir e gerir a conta bancária da associação/cooperativa, participar de reuniões, viajar para participar de feiras e encontros, contribuir com as lutas sociais, dividir o trabalho doméstico com os homens durante as atividades de gênero nos assentamentos, dando visibilidade ao trabalho das mulheres. Situação em muito se assemelha às conquistas das mulheres que atuam nas redes descritas neste trabalho.

Apesar das diferenças na estrutura, tempo de atuação e objetivos, os diversos grupos representados na rede construída neste trabalho (Figura 1) desempenham papéis complementares. Além de atenderem as particularidades das suas instituições ou comunidades, há várias conexões, feiras, cursos, oficinas de capacitação, simpósios, congressos e encontros que permitem que elas se conheçam, troquem, estabeleçam trocas e se fortaleçam. O estabelecimento dessas relações se deu principalmente nos últimos 20 anos, sendo ainda muito recentes, mas com resultados que indicam mudanças no contexto ambiental, político, social e econômico na vida e nas famílias dessas mulheres e das comunidades. Pode-se dizer que o fluxo entre as comunidades está em construção, com grande troca de saberes entre as comunidades e as organizações a elas vinculadas. $\mathrm{Na}$ Cerrapan, onde há uma grande interação entre as mulheres de diferentes comunidades, considerando a agenda política, agenda de produção e agenda de conservação, as conexões se estabelecem com o debate sobre direitos humanos, os impactos das grandes obras de infraestrutura, o modo de fazer política junto aos poderes públicos, o acesso ao mercado, qualificação e melhoramento de produtos, acesso à água limpa, boas práticas de manejo de espécies nativas e recuperação de nascentes. Percebe-se que há uma grande transformação social, por meio de ações sustentáveis, de empoderamento em seus empreendimentos, que vão além da dimensão monetária, situação discutida por Santos e Haubrich (2018).

Os EES desempenham, mediante o controle dos meios de produção, uma atividade caracteristicamente socioeconômica. Neste sentido, a cooperação é um elemento estratégico, que cria condições para o melhor desenvolvimento do trabalho social. Vai além do trabalho familiar individual e da propriedade privada, objetivando um processo produtivo que pratique 
o trabalho socialmente dividido, como uma planificação dos vários momentos produtivos. A participação mais efetiva da mulher nas atividades cooperativas exige a superação de alguns entraves e uma maior capacidade de inserção num meio geralmente masculino. Estudos com enfoque na mulher e na sua participação em cooperativas no Brasil têm mostrado que nas cooperativas que trabalham com o voto familiar, as mulheres ficam de lado dificultando sua participação (BUENO e KNUPPEL, 2016). O estudo de Zimmermann et al. (2020), por sua vez, mostrou que a maioria das mulheres tem contato com a cooperativa através da relação mais direta do esposo.

Mesmo sendo empreendimentos baseados nas relações de troca, produção e solidariedade, por estarem inseridos em um ambiente competitivo do mercado capitalista, praticado principalmente por organizações bem estruturadas de controle de estoques e logística, é essencial para os EES a apropriação de um conjunto de conhecimentos, ferramentas, processos e práticas, que ampliem significativamente sua capacidade de organização social, econômica, comercial e sua interação com a Rede. Uma rede densa e organizada representa um incremento representatividade e na capacidade de atuação e articulação nos campos públicos e privado para o conjunto dos EES e das mulheres, ampliando sua capacidade de acesso às políticas públicas, de qualificação dos seus componentes, e de organização coletiva de iniciativas de cooperação econômica e comercial.

A participação de mulheres das comunidades rurais nos eventos e feiras, fora das comunidades, tem sido importante para fortalecer o papel de lideranças e melhorar a autoestima. Ao compartilharem suas experiências durante cursos e simpósios, elas também têm a oportunidade de conhecer os membros dos projetos que muitas vezes não vão até as comunidades, mas atuam em outros âmbitos. Nas visitas aos laboratórios e herbários, com o contato com seus pares, de outras comunidades, todas podem formar seu próprio conceito a respeito das atividades que desenvolvem e como ele se relaciona com outros setores da sociedade.

A participação de mulheres no Programa de Extensão desenvolvido na UFMS, com uma produção científica voltada ao tema de plantas alimentícias nativas, reflete a situação identificada nessa instituição em 2017, na qual as mulheres são responsáveis por praticamente a metade da força de trabalho (UFMS 2017), situação também observada em outras instituições de ensino superior brasileiras (RICOLDI e ARTES, 2016).

As ações iniciais no processo de sensibilização das comunidades do Pantanal pelo Programa Sabores contavam com informações contextualizadas decorrentes de ações de 
pesquisa na área de Etnobotânica que indicavam a condição de êxodo dos jovens das comunidades e de risco de descontinuidade no processo de transmissão de conhecimentos (BORTOLOTTO e GUARIM NETO, 2004; BORTOLOTTO e AMOROZO, 2014). O fato de alguns produtos processados serem mais conhecidos por mulheres idosas (BORTOLOTTO et al., 2015), indica que há necessidade de transmissão dos conhecimentos às mais jovens. $\mathrm{O}$ distanciamento de jovens das comunidades é um fator preocupante e que fragiliza as famílias e o processo de valorização de conhecimentos locais.

Essa é uma situação a ser enfrentada em outras comunidades nos diferentes estados brasileiros. Numa comunidade rural no Semiárido do Piauí, por exemplo, os conhecimentos tradicionais associados à extração e uso do azeite de "gergelim preto" têm importância biocultural para a comunidade, sendo empregado para tratar diversos problemas de saúde (SIQUEIRA et al., 2020). Entretanto, a manutenção dessas práticas na comunidade está ameaçada pelo forte desinteresse entre os mais jovens, sobretudo do gênero masculino, por se acreditar ser tarefa da mulher. As ações desenvolvidas contribuem para gerar alternativas de emprego e renda no local, mas são necessárias ações continuadas e complementares, envolvendo outras áreas.

A produção de alimentos e o manejo sustentável de recursos naturais são desenvolvidos pelas mulheres, que produzem alimento para dentro da comunidade e fazem das espécies nativas alimentos ricos em sabores. Somados aos vastos nutrientes naturalmente presentes nos frutos, castanhas, palmitos e outras partes, os alimentos têm valor inestimável ao consumidor, pois não são apenas produtos; eles vêm alinhados com as práticas de conservação ambiental. Conectadas em rede, as mulheres abrem espaço para um sistema produtivo no MS que garante a produção de alimentos de forma justa e sustentável. Essa é uma grande contribuição para que o Brasil consiga cumprir compromissos firmados internacionalmente, como os Objetivos de Desenvolvimento Sustentável (ODS), que devem ser atingidos até 2030 (PNUD, 2015), especialmente em relação à erradicação da fome e a discriminação contra mulheres.

São elas as principais responsáveis pelo envolvimento dos jovens em atividades das comunidades. A preocupação demonstrada com o êxodo da área rural para as zonas urbanas e a percepção da ameaça aos saberes locais, história e cultura com a evasão da população jovem, que na maioria das vezes sai para estudar e buscar melhores condições de vida, é um alerta para a definição de políticas públicas que atentem para essa situação. O papel protagonista das mulheres pantaneiras e cerradeiras nesse processo é notável e vem se 
desenvolvendo muito fortemente nesta última década, envolvendo a luta pela permanência dos povos tradicionais no território.

A execução das tarefas domésticas e as atividades de trabalho é um ponto crítico das desigualdades de gênero, que tendem ao desequilíbrio. Isso se tornou mais grave no ano de 2020, em relação a pandemia do Coronavírus 2019 (COVID-19). Um levantamento recente (VIGLIONE, 2020) apresenta uma compilação de resultados de investigações realizadas por diversos grupos de pesquisa em diferentes países, que analisam a produtividade das mulheres cientistas durante a pandemia. Com diferentes métodos e perspectivas, todas as pesquisas resultam numa diminuição da produtividade. Esses dados tornam mais evidentes a situação enfrentada por mulheres no âmbito científico, agravada durante o período de isolamento atual.

As dificuldades enfrentadas pelas mulheres que fazem parte das comunidades extrativistas, como a sobrecarga de trabalho, cuidados com a família e dificuldade de lazer, poderiam ser fatores desmotivadores para seguir em frente. Ao invés disso, as mulheres demonstram uma grande capacidade de resiliência. Uma vez envolvidas com a vida pública, se veem na condição de repensar seus papéis. Ainda hoje, vivemos em uma sociedade em que as mulheres são responsabilizadas pelo espaço doméstico e os cuidados com a casa e os membros da família, em seus cotidianos. Isso certamente causa, para muitas dessas mulheres, a sobreposição de tarefas, havendo a inclusão de outras atividades, como o trabalho fora de casa com o agroextrativismo.

Suas capacidades de conciliar tudo isso e ajustar as expectativas da família sobre suas funções dentro e fora do espaço privado são um desafio. Muito comum é o envolvimento de familiares (companheiras, mães e filhas) que passam a contribuir diretamente com atividades do trabalho e dos grupos sociais organizados na comunidade. Este é um passo entendido como positivo, visto que, pela perspectiva das relações sociais de gênero, é preciso que se entenda e se transforme a dinâmica social, visando o cenário em que as mulheres estão à frente da vida pública também e, para isso, nada melhor que o envolvimento de todas e todos nas diversas atividades e responsabilidades.

Nesse aspecto, a rede funciona como suporte para conectar diferentes espaços e é importante para a reflexão e o debate. As mulheres equilibram, com altíssimo custo, todos esses afazeres, atividades e cuidados com a família. Se partimos da nossa experiência, acumulamos uma série de atividades de trabalhos no público e privado, que acabamos por equilibrar, mas, cada uma de nós sabe a que preço. Isso tudo está relacionado ao papel social imposto às mulheres. 
As comunidades incluídas nesta rede têm um conjunto de conhecimentos distintos em relação às plantas alimentícias. Nos assentamentos rurais, há um grande interesse pelas espécies nativas e um processo contínuo de aprendizagem e troca de experiências. Nas comunidades tradicionais e indígenas, há uma ressignificação de alimentos tradicionais usados na dieta que acaba por valorizá-los, assim como, os conhecimentos associados, que em alguns casos, estão em processo de erosão (BORTOLOTTO et al., 2015). Nas duas situações, são grandes as possibilidades para geração de produtos alimentícios, considerando, além dos saberes, a riqueza de espécies alimentícias no MS (BORTOLOTTO et al., 2018). As mulheres de institutos de pesquisas, organizações não governamentais e as lideranças locais desempenham um papel de protagonismo nesse processo que tem sido observado também em outras comunidades, com resultados associados à SAN e à manutenção da cultura e dos modos de vida. No caso das mulheres da Associação Regional das Produtoras Extrativistas do Pantanal - MT, uma nova fase de relação com os recursos naturais por meio da produção extrativista sustentável fortaleceu a agricultura familiar, preservando a biodiversidade com a promoção da SAN (MENDES et al., 2014). A pesquisa de Agrícola (2019) sobre mulheres cerradeiras da área urbana e rural no sudoeste de Goiás aborda os conhecimentos, tradições e resistências de 20 mulheres que têm um estreito relacionamento com o Cerrado, adquirido ao longo de suas vidas e que acaba por manter a cultura e os modos de vida.

As mulheres também participam de outras redes, como a Articulação Pacari, que é uma rede socioambiental formada por grupos comunitários que praticam a medicina tradicional no Cerrado, com forte presença de mulheres (DIAS e LAUREANO, 2009). Esse conhecimento tradicional das mulheres associado às plantas é tão significativo que as raizeiras do Cerrado requisitaram e garantiram a valorização desse conhecimento, manejo e uso, mediante a publicação do "Protocolo Comunitário Biocultural do Cerrado - Direito consuetudinário de praticar a medicina tradicional" (2014). Conforme descrito no referido protocolo, os direitos consuetudinários são valores, cosmovisões, práticas que identificam e são reivindicadas por determinada população, cuja tradição é passada de geração em geração, num movimento vivo e contínuo (DIAS e LAUREANO, 2014).

\section{CONCLUSÕES}

A rede apresentada conecta mulheres da Ciência e da Sociedade em prol da valorização da diversidade biocultural e a conservação das plantas alimentícias do Cerrado e do Pantanal. O estímulo feito para aproveitamento de frutos, castanhas e outras partes de 
plantas, nas últimas duas décadas no MS, desencadeia uma série de demandas que envolvem mulheres de várias comunidades, organizações governamentais e não governamentais. $\mathrm{O}$ CEPPEC teve um papel pioneiro no MS em relação à organização social de mulheres voltadas ao extrativismo e ainda se mantém atuante, de forma solidária, compartilhando suas experiências e enfrentando novos desafios. A CerraPan é um estímulo para a autonomia econômica das mulheres, fortalecendo também a resiliência territorial, a conservação do ambiente e a luta pelo acesso aos direitos das comunidades, para melhoria das condições de vida. O Movimento de Economia Solidária representa uma força de enfrentamento para dar suporte aos grupos que praticam o extrativismo, especialmente por comunidades indígenas e projetos de Assentamento de Reforma Agrária. A UFMS desenvolve um papel estratégico na produção científica relacionada às plantas alimentícias nativas e representa uma instituição com grande legitimidade do trabalho das mulheres na Ciência associada às atividades de extensão. A ECOA é uma organização estratégica para a mobilização e suporte às comunidades que trabalham com as questões socioambientais.

As mulheres das diversas comunidades e das mulheres das instituições articuladas a elas (inclusive nós, autoras deste trabalho), tomaram para si, uma atividade negligenciada na sociedade. Enxergar alimento em "frutos do mato" e transformar esses frutos, com sabores diversos, em bolos, tortas, sucos e compotas tem sido uma tarefa desafiadora e gratificante. Ingressar num mundo de negócios até há pouco tempo um universo considerado masculino, ainda está em processo. O papel das mulheres na valorização e conservação das plantas alimentícias do Cerrado e Pantanal no MS cresce a cada dia, sendo fundamental um olhar que analise e impulsione esse movimento em rede.

\section{AGRADECIMENTOS}

Especial agradecimento a todas as mulheres que participaram dos projetos mencionados aqui e aos seus familiares e comunidades. À Universidade Federal de Mato Grosso do Sul pelo apoio financeiro nos editais PAEXT/UFMS e ao Programa de PósGraduação em Biologia Vegetal (PPGBV/UFMS), pelo suporte às atividades da primeira e última autora. Ao acadêmico do PPGBV/UFMS e estagiário da ECOA, Thiago M. O. Saiefert pela elaboração do Mapa (Figura 1 deste trabalho). Ao Conselho Nacional de Desenvolvimento Científico e Tecnológico (CNPq), pelas bolsas fornecidas aos acadêmicos de mestrado da UFMS que colaboraram com o Programa Sabores. Pelo suporte financeiro a projetos, agradecemos ao CNPq, ao Ministério da Educação (SESU/PROEXT); à União 
Europeia, ao Fundo de Parceria para Ecossistemas Críticos (CEPF, na sigla em inglês para Critical Ecosystem Partnership Fund); a Charles Stewart Mott Foundation; ao Serviço Nacional de aprendizagem do Cooperativismo (SESCOOP), ao Fundo Brasileiro para a Biodiversidade (FUNBIO), à Fundação Banco do Brasil (FBB), ao Banco Nacional de Desenvolvimento Econômico e Social (BNDES) e à Organização das Nações Unidas Mulheres (ONU - Mulheres). Às instituições das autoras: ECOA, UNICAFES, FIOCRUZ e UFMS. Às revisoras, pelas sugestões apresentadas.

\section{REFERÊNCIAS BIBLIOGRÁFICAS}

AGRÍCOLA, J. M. A. Mulheres cerradeiras: conhecimentos, tradições e resistências. 269 f. Tese (Doutorado em Geografia) - Universidade Federal de Goiás, Jataí, 2019.

AMSALU, M.; BEZIE, Y.; FENTAHUN, M.; ALEMAYEHU, A.; AMSALU, G. Use and Conservation of Medicinal Plants by Indigenous People of Gozamin Wereda, East Gojjam Zone of Amhara Region, Ethiopia: An Ethnobotanical Approach. Evidence-Based Complementary and Alternative Medicine, v, p.1-23, 2018.

ANBACHA, A. E.; KJOSAVIK, D. J. Borana women's indigenous social network-marro in building household food security: Case study from Ethiopia. Pastoralism: Research, Policy and Practice. [S.1] v. 8 , n. 29 , p. 2-12, 2018.

ARAKAKI, D. G.; CANDIDO, C. J.; SILVA, A. FERNANDES DA; GUIMARÃES, R. DE C. A.; HIANE, P. A. In vitro and in vivo antioxidant activity of the pulp of Jatobá-do-cerrado. Ciência e Tecnologia de Alimentos (Online), Campinas, v. 36, n.1, p. 166-170, 2016. Disponível em: $<$ http://www.scielo.br/scielo.php?script=sci_arttext\&pid=S0101-

20612016000100166\&lng=en\&nrm=iso $>$. Acesso em: 14 nov. 2020.

BARBOSA, M. M.; MACEDO, M. L. R.; HIANE, P. A.; DAMASCENO JUNIOR, G. A.; BRAGA NETO, J. A.; MENDONCA, L. A. B. M.; GUIMARÃES, R.C.; NASCIMENTO, V. A. Proteins of Oryza latifolia from brazilian Pantanal: impact on the use of aminoacids and weight gain of animals. International Journal of Development Research, [S.1], v. 07, n.11, p. 16885-16891, 2017.

BEE, B. "Si no comemos tortilla, no vivimos:" women, climate change, and food security in central Mexico. Agricultura e Valores Humanos, [S.1], v. 31, n. 4, p. 607-620, 2014.

BERTAZZONI, E. C.; DAMASCENO-JÚNIOR, G. A. Aspectos da biologia e fenologia de Oryza latifolia Desv. (Poaceae) no Pantanal sul-mato-grossense. Acta Botanica Brasilica, Porto Alegre, v. 25, p. 476-486, 2011. Disponível em: https://doi.org/10.21826/2446-8231201873s101. Acesso em: 4 out. 2020.

BORTOLOTTO, I. M.; AMOROZO, M. C. M. Aspectos históricos e estratégias de subsistência nas comunidades localizadas ao longo do rio Paraguai em Corumbá-MS. In: MORETTI, E. C., BANDUCCI JUNIOR, Á. (Eds) Pantanal: territorialidades, culturas e diversidade. Campo Grande, Editora da UFMS, 2012. p.57-88.

BORTOlOtTO, I. M.; DAMASCENO-JUNIOR, G. A.; POTT, A. Preliminary list of native food plants of Mato Grosso do Sul, Brazil. Iheringia - Série Botânica. 73:101-116, 2018. Disponível em: https://doi.org/10.21826/2446-8231201873s101. Acesso em: 4 out. 2020. 
BORTOLOTTO, I. M.; GUARIM NETO, G. Albuquerque: aspectos históricos, sócioambientais e educacionais do Distrito de Albuquerque, Corumbá, no Pantanal Sul-mato-grossense.. Revista de Geografia, Campo Grande, v.1, n.19, p. 42-52, 2004.

BORTOLOTTO, I. M. (org.). Conservação da biodiversidade, alimentos e cultura em Mato Grosso do Sul. Campo Grande: Editora UFMS, 2017. 68 p. (Coleção Sabres do Cerrado e do Pantanal, v. 2)

BORTOLOTTO, I. M., AMOROZO, M. C. M.; GUARIM NETO, G.; OLDELAND; DAMASCENOJUNIOR, G. A. Knowledge and use of wild edible plants in rural communities along Paraguay River, Pantanal, Brazil. Journal of ethnobiology and ethnomedicine, v.11, p. 46-46, 2015.

BORTOlOtTO, I. M., SELEME, E. P.; DE ARAÚJO, I. P. P.; MOURA, S. DE S.; SARTORI, Â. L. B. Conhecimento local sobre plantas alimentícias nativas no Chaco brasileiro. Oecologia Australis, v. 23, n. 4, p. 768-779, 2019.

BORTOLOTTO, I. M.; HIANE, P. A.; ISHII, I. H.; SOUZA, P. R.; CAMPOS, R. P.; GOMES, R. J. B.; FARIAS, C. S.; LEME, F. M.; ARRUDA, R. C. O.; COSTA, L. B. L. C.; DAMASCENOJUNIOR, G. A. A knowledge network to promote the use and valorization of wild food plants in the Pantanal and Cerrado, Brazil. Regional Environmental Change. v. 17, n. 5, p. 1329-1341, 2017.

BRASIL. Ministério do Trabalho. Secretaria Nacional de Economia Solidária. Sistema Nacional de Informações de Economia Solidária. Atlas da Economia Solidária no Brasil 2013. Brasília: MTE, SENAES, 2013.

BRESSAN, D.; DEL RÉ, P. V.; SANTOS, E. F. dos; GUIMARÃES, R. de C. A. Qualidade na Produção de Alimentos. Campo Grande: Editora UFMS, 2017. 64 p. (Coleção Saberes do Cerrado e Pantanal, v. 5, n.1).

BUENO, L. B.; OLIVEIRA. T. Minidocumentário Fruto (a) colhido. Disponível em: https://www.youtube.com/watch?v=S1GqKHNZKPM. Acesso em: 23 set. 2020.

BUENO, V. K.; KNUPPEL, M. A. C. A participação da mulher no cooperativismo: um estudo a partir de pesquisas em relação à temática. Campo Grande, 2016. Disponível em: https://bit.ly/2Wc3xye. Acesso em: 06 nov. 2020.

CAMPOS, R. P.; HIANE, P. A.; RAMOS, M. I. L.; RAMOS FILHO, M. M.; MACEDO, M. L. R. Conservação pós-colheita de guavira (Campomanesia sp.). Revista Brasileira de Fruticultura, Jaboticabal, v. 34, p. 41-49, 2012.

CAMPOS, R. P.; SILVA, M. J. F.; FARIAS, C. da S.; FRAGOSO, M. R.; CANDIDO, C. J. Elaboração e Caracterização de Farinha da Casca de Pequi. Cadernos Agroecológicos, v. 11, n.2, p. $1-12,2016$.

CARDOZO, C.; INADA, A.; MARCELINO, G.; FIGUEIREDO, P.; ARAKAKI, D.; HIANE, P.; CARDOSO, C.; GUIMARÃES, R. de C.; FREITAS, K. Therapeutic Potential of Brazilian Cerrado Campomanesia Species on Metabolic Dysfunctions. Molecules, v. 23, n.9, p. 1-17, 2018.

CHAMORRO, G.; COMBÉS, I. Povos indígenas em Mato Grosso do Sul: História, cultura e transformações sociais. Dourados: Editora UFGD, 2015. 934 p.

DAL SOGLIO, F. K.; OGLIARI, J. B.; MACHADO, A. T.; ALMEIDA, J.; BOEF, W. S. de. Metodologias participativas e a geração de biotecnologias apropriadas para o desenvolvimento rural sustentável. In: BOEF, W. S. de; THIJSSEN, M. H.; OGLIARI, J. B.; STHAPIT, B. R. (Org.). 
Biodiversidade e agricultores: fortalecendo o manejo comunitário. Porto Alegre: L \& PM, p. 210218, 2007.

DAMASCENO-JUNIOR, G. A.; BORTOLOTTO, I. M.; SARTORI, A. L. B.; POTT, A.; SOUZA, P. R. de. Tipos de vegetação em Mato Grosso do Sul: fontes de plantas alimentícias. Campo Grande: Editora UFMS, 2017. 61 p. (Coleção saberes do Cerrado e Pantanal, v. 2, n.1)

DAMASCENO-JUNIOR, G. A.; SOUZA, P. R.; BORTOLOTTO, I. M.; RAMOS, M. I. L.; HIANE, P. A.; BRAGA NETO, J. A.; ISHII, I. H.; COSTA, D.C.; RAMOS-FILHO, M. M.; GOMES, R. J. B.; BARBOSA, M. M. RODRIGUES, R. B. Sabores do Cerrado \& Pantanal: Receitas e boas práticas de aproveitamento. Campo Grande: Editora UFMS, 2010, 141 p.

DIAS, F. R. T.; GALVANI, F. Custeio e Investimento do Sistema Artesanal de Produção da Farinha de Bocaiuva. Corumbá: Editora Pantanal, 2017, 18 p. (Série Documentos, 147). Disponível em: https://ainfo.cnptia.embrapa.br/digital/bitstream/item/170899/1/Fernando-bocaiuva-final.doc147.pdf. Acesso em: 20 mai. 2020.

DIAS, J. E.; LAUREANO, L. C. (Org.). Protocolo comunitário biocultural das raizeiras do Cerrado: direito consuetudinário de praticar a medicina tradicional. Turmalina: Articulação Pacari, 2014. Disponível em: http://www.pacari.org.br/protocolo-comunitario-biocultural-dasraizeiras-do-cerrado/. Acesso em: 20 mai. 2020.

DIAS, J. E.; LAUREANO, L. C. (Org.). Farmacopéia popular do Cerrado. Goiás: Articulação Pacari, 2009. Disponível em: http://www.pacari.org.br/farmacopeia-popular-do-cerrado/livrofarmacopeia-popular-do-cerrado/ Acesso em: 6 out. 2020.

DIEGUES, A. C. Conhecimentos, práticas tradicionais e a etnoconservação da natureza. In: Lúcia CUNHA, H. O. C., FLORIANI, D. Diálogos de Saberes Socioambientais: desafios para epistemologias do Sul. Revista Desenvolvimento e Meio Ambiente, Curitiba, v. 50, especial, p. 116$126,2019$.

DONADON, J. R.; CAMPOS, R. P. Colheita e pós-colheita de frutos nativos. Campo Grande: Editora UFMS, 2017. 68 p. (Coleção Saberes do Cerrado e Pantanal, v. 3, n.1

DONADON, J. R.; CORREA, G. C.; BORSATO, A. V.; CANDIDO, C. J.; CAMPOS, R. P. Processo de Obtenção e Avaliação Química de Doce Cristalizado de Bocaiuva. Cadernos Agroecológicos, v. 11, n. 2, 2017.

DONADON, J. R.; THEODORO, Â. C. C.; CAMPOS, R. P.; PRATES, M. F. O.; BALBINOTI, T. de C. V. Frutos Nativos: doces cristalizados e geleias. Campo Grande: Editora UFMS, 2020. 64 p. (Coleção Saberes do Cerrado e Pantanal, v. 7).

ECOA. Página inicial. Campo Grande, 2020. Disponível em: https://ecoa.org.br. Acesso em: 14 nov. 2020.

ECOA. CerraPan - Rede de Mulheres Produtoras do Cerrado e Pantanal. Campo Grande, 2020. Disponível em: https://ecoa.org.br/cerrapan/. Acesso em: 10 jun. 2020.

ECOA. Extrativismo e as Populações Tradicionais em Mato Grosso do Sul, Estudo Preliminar. Campo Grande, 1994. (Relatório).

ECOA. Mapa interativo das Comunidades na Bacia do Alto rio Paraguai. Campo Grande, 2018. 1 mapa, color. Disponível em: https://ecoa.org.br/mapa-interativo/. Acesso em: 30 mai. 2020. 
FAO - FOOD AND AGRICULTURE ORGANIZATION OF THE UNITED NATIONS. The state of Food and Agriculture - Women in agriculture (2010-2011). Rome, 2011. Disponível em: http://www.fao.org/3/i2050e/i2050e.pdf. Acesso em 5 out. 2020.

FBES - FÓRUM BRASILEIRO DA ECOMOMIA SOLIDÁRIA. Página inicial. Disponível em: https://fbes.org.br). Acesso em: 14 nov. 2020.

FERNANDES, D. S.; DONADON, J. R.; RANGEL, T. F; GUIMARÃES, R. de C. A.; CAMPOS, R. P., LIMA, L. B. De; HIANE, P. A. Quality of roasted baru almonds stored in different packages. Food Science and Technology, Campinas, EpubOctober 16, 2020. Disponível em: $<$ http://www.scielo.br/scielo.php?script=sci_arttext\&pid=S0101-

20612020005024202\&lng=en\&nrm=iso >. Acesso em: 14 Abr 2021.

FIORAVANTE, M. B.; HIANE, P. A.; CAMPOS, R. P.; CANDIDO, C. J. Qualidade nutricional e funcional de biscoito de farinha de caraguatá (Bromelia balansae Mez). Revista UNIABEU, Campinas, v. 9, p. 221-235, 2016.

FIORAVANTE, M. B.; HIANE, P. A.; BRAGA NETO, J. A. Elaboration, sensorial acceptance and characterization of fermented flavored drink based on water-soluble extract of baru almond. Ciência Rural, Santa Maria, v. 47, n.9, p.1-6, 2017.

GEERTZ, C. A interpretação das culturas. Rio de Janeiro: LTC, 2008.

GEIFULS, F. 80 herramientas para el desarrollo participativo: diagnóstico, planificación, monitoreo, evaluación. San José: IICA, 2002.

GONDIM, E. X.; FERREIRA, B. H. DOS S.; REIS, L. K.; GUERRA, A.; ABRAHÃO, M.; AJALLA, A. C.; VOLPE, E.; GARCIA, L. C. Growth, flowering and fruiting of Campomanesia adamantium (Cambess) O. Berg intercropped with green manure species in Agroforestry Systems. Agroforestry Systems, v. 2, 2020. Disponível em: https://doi.org/10.1007/s10457-020-00533-2. Acesso em: 5 nov. 2020.

JUNQUEIRA, J. R. DE J.; THEODORO, Â. C. C.; BRITES, B. F.; BRAGA NETO, J. A.; HIANE, P. A.; GUIMARÃES, R. DE C. A.; DONADON, J. R., BOGO, D. Frutos Nativos: produção de farinhas. Campo Grande: Editora UFMS, 2020. 62 p. (Coleção Saberes do Cerrado e Pantanal, v. 6, n.3).

KIMURA, J., SUZUKI, Y.; MIZUMURA, K. Report on the Women in Physiology Symposium in IUPS 2009. Journal Physiology Science, v. 60, n. 3, p. 227-234, 2010. Disponível em: https://doiorg.ez51.periodicos.capes.gov.br/10.1007/s12576-010-0088-9. Acesso em: 17 abr. 2020.

LEAL, L. S. G.; FILIPAK, A.; DUVAL, H. C.; FERRAZ, J. M. G.; FERRANTE, V. L. S. B. Quintais produtivos como espaços da agroecologia desenvolvidos por mulheres rurais. Perspectivas em Diálogo, Naviraí, v. 7, n. 14, p. 31-54, 2020.

LIBERATO, R. S.; MOUTINHO, L.; NORONHA, I.; BAGNOL, B. Soberania Alimentar no Machimbombo e na aldeia: gênero na perspectiva Sul-Sul. Revista Estudos Feministas, Florianópolis, v. 27, n. 3, p. 1-15, 2019.

LIMA, N. V; ARAKAKI, D. G.; TSCHINKEL, P. F. S. T.; MELO, E. S. DE P.; CAIRES, A. R. L.; FIGUEIREDO, P. S.; GUIMARÃES, R. DE C. A.; HIANE, P. A.; NASCIMENTO, V. A. V. Determination of macro and microelements in whole fruit of Campomanesia adamantium (Cambess) O. Berg and evaluation of their nutritional potential for children, adolescents and pregnant women. International Journal of Development Research, v. 07, p. 13272-13279, 2017. 
LOON, J. V. Network. Theory, Culture \& Society, v. 23, n. 23, p. 307-314, 2006.

MELO, E.; MICHELS, F.; ARAKAKI, D.; LIMA, N.; GONÇALVES, D.; CAVALHEIRO, L.; OLIVEIRA, L.; CAIRES, A.; HIANE, P.; NASCIMENTO, V. First Study on the Oxidative Stability and Elemental Analysis of Babassu (Attalea speciosa) Edible Oil Produced in Brazil Using a Domestic Extraction Machine. Molecules, v. 24, n. 23, p. 4235-4256, 2019.

MENDES, M. F.; NEVES, S. M. A. da S.; NEVES, R. J.; SILVA, T. P. da A organização das mulheres extrativistas na região sudoeste mato-grossense, Brasil. Revista Estudos Feministas, Florianópolis, v. 22, n. 1, 2014.

MINAYO, M. C. de S. (Org.). Pesquisa Social: teoria, método e criatividade. Petrópolis: Vozes, 1998. $80 \mathrm{p}$.

NOGUEIRA, L. M. S.; FIGUEIREDO, P. S.; CANDIDO, C. J.; MIYAGUSKU, L.; CAMPOS, R. P.; Hiane, P. A.; GUIMARAES, R. C. A.; ARECO, A. E. T. Caracterização e aceitação sensorial de frozen yogurt formulado com polpa de laranjinha de pacu (Pouteira glomerata (Miq.) Radlk) e culturas probióticas. AMBIÊNCIA, v. 14, n. 1, p. 174-185, 2018.

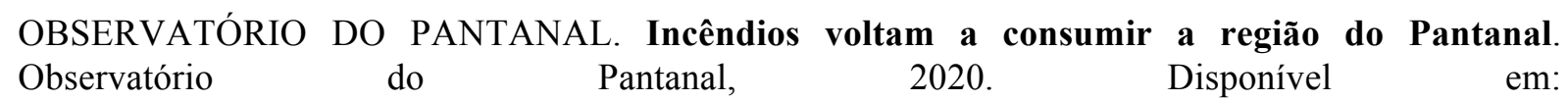
https://observatoriopantanal.org/2020/04/20/incendios-voltam-a-assolar-a-regiao-do-

pantanal/\#https://observatoriopantanal.org/pt-br/\#!/about_section. Acesso em: 31 mai. 2020.

PRATES, M. F. O.; CAMPOS, R. P.; HIANE, P. A.; RAMOS FILHO, M. M.; MOURA, S. C. S. R. Canjiqueira fruit jelly: sensory evaluation and stability during storage. International Journal of Development Research, v. 07, p. 17566-17571, 2017.

PRATES, M. F. O.; CAMPOS, R. P.; SILVA, M. M. B.; MACEDO, M. L. R.; Hiane, P. A.; RAMOS FILHO, M, M. Nutritional and antioxidant potential of canjiqueira fruits affected by maturity stage and thermal processing. Ciência Rural (UFSM. Impresso), v. 45, n.3, p. 399-404, 2015.

PRATES, M.F.O.; CAMPOS, R. P.; HIANE, P.A.; FILHO, M.M.R.; MACEDO, M. L. R. Quality index and bioactive compounds during postharvest of Byrsonima cydoniifolia A. Juss. fruits: effect of maturity stage. Acta Horticulturae, v. 1, p. 101-110, 2018.

RAMOS, M. DE L. M.; RODRIGUES, G. DA C. G.; SOARES, W. R. G.; HIANE, P.A.; RAMOS, M. I. L.; ALMEIDA, J. A. DE; SANCHES, F. L F. Z. Suplementação com amêndoa de bacuri na composição corporal de ratos submetidos ao exercício. Revista Brasileira de Medicina do Esporte, São Paulo, v. 23, n. 4, p. 294-299, 2017.

RICOLDI, A. E; ARTES, A. Mulheres no ensino superior brasileiro: espaço garantido e novos desafios. exæquo, v. 1, n. 33, p. 149-161, 2016.

SABORES DO CERRADO E PANTANAL. Universidade Federal de Mato Grosso do Sul. Página inicial. Campo Grande, 2020. Disponível em: https://sabores.ufms.br Acesso em: 14 nov. 2020.

SANCHES, F. LA F. Z.; SEMIDEI, R.; DA CUNHA, F. C.; DE SOUZA, R. S.; MACEDO, M. L. R.; HIANE, P. A.; RAFACHO, B. P. M. Protein supplement obtained from almonds of bacuri fruit (Attalea phalerata Mart. Ex Spreng.): elaboration, nutritional characterization and sensory acceptability. International Journal for Innovation Education and Research, v. 8, n. 1, p. 232$247,2020$. 
SALES, C. M. V. Mulheres rurais: tecendo novas relações e reconhecendo direitos. Revista Estudos Feministas, Florianópolis, v. 15, n. 2, p. 437-443, 2007.

SANTOS, F. B. O dos; RAMOS, M. I. L.; Miyagusku, L. Antimicrobial activity of hydroalcoholic extracts from genipap, baru and taruma. Ciencia Rural, Santa Maria, v. 47, n. 8, p. 1-6, 2017.

SANTOS, M.; ALMEIDA, G. C. R.; CANDIDO, C. J.; ZAMPIERI, D. F.; VARGAS, M. O. F.; SILVA, A. F.; NASCIMENTO, V. A.; NOVELlO, D.; HIANE, P.A.; SANTOS, E. F. Characterization and sensorial analysis of diet cookies prepared with different levels of cumbaru nut. International Journal of Development Research, v. 8, p. 21136-21140, 2018.

SANTOS, M. M. R.; FERNANDES, D. S.; CÂNDIDO, C. J.; CAVALHEIRO, L. F.; SILVA, A. F. da; NASCIMENTO, V. A. do; RAMOS FILHO, M. M.; SANTOS, E. F. dos; HIANE, P. A. Physicalchemical, nutritional and antioxidant properties of tucumã (Astrocaryum huaimi Mart.) fruits. Semina. Ciências Agrárias (ONLINE), Londrina, v. 39, n. 4, p. 1517, 2018.

SCHAAF, A. V. DER, Jeito de mulher rural: a busca de direitos sociais e da igualdade de gênero no Rio Grande do Sul. Sociologias, Porto Alegre, v. 5, n. 10, p. 412-442, 2003.

SELEME, E. P.; BORTOLOTTO, I. M.; SARTORI, A. L. B. Riqueza e uso de recursos vegetais por moradores do Chaco brasileiro. In: Silva, C. J.; Guarim Neto, G. (eds). Comunidades tradicionais do Pantanal. UNEMAT/Entrelinhas, Cáceres/Cuiabá, p. 57-73, 2020.

SIGRIST, M. R.; STEFANELlO, T. H.; DE SOUZA, C. S.; VARGAS, W.; ALMEIDA, K. S. M.; LAROCA, S.; MANSANO, V. F. Phenology and pollination ecology of Prosopis rubriflora (Leguminosae, Mimosoideae), a species from the semi-arid Brazilian Chaco. Brazilian Journal of Botany, v. 41, p. 103-115, 2018.

SILVA, G. T.; RAMIRES, A. D.; CANDIDO, C. J.; ALMEIDA, J. A.; HIANE, PRISCILA AIKO; BOGO, D.; NASCIMENTO, V. A.; ANTONIOLLI, A. B.; GUIMARAES, R. C. A. Development of frozen yogurt lactose-freeplus Campomanesia sp. International Journal of Development Research, v. 8, n. 2, p. 18935-18939, 2018.

SILVA, L. M. G. E. da.; PRATES, M. F. de O.; BOGO, D.; BRAGA NETO, J. A. Higiene e boas práticas na manipulação de frutos nativos. Campo Grande: Editora UFMS, 2017. 68 p. (Coleção Saberes do Cerrado e Pantanal, v. 4)

SILVA, V. M. da; GUIMARÃES, R. de C. A; CAMPOS, R. P.; BORSATO, A. V.; HIANE, P. A.; DONADON, J. Drying and storage of macaúba fruit: chemical andoxidative stability. Seminário de Ciências Agrárias, v. 41, n. 3, p. 865-878, 2020.

SIQUEIRA, J. I. A. de; MACHADO, T. de J.; LEMOS, J. R. Bioculturalidade associada à extração e uso do azeite de uma etnovariedade de Sesamum L. (Pedaliaceae): Uma abordagem etnobotânica em uma comunidade rural no Semiárido do Piauí (Nordeste do Brasil). Ethnobotany Research and Applications, v. 19, n. 11, p. 1-26. 2020.

SOUZA, R. S. de; CUEllaR, J. P.; DONADON, J. R.; GUIMARÃES, R. de C. A. Compostos bioativos em geleia de bocaiuva com maracujá. Multitemas (UCDB), v. 24, n. 57, p. 79-94, 2019.

STAMARSKI, C S.; SON HING, L. S. Gender inequalities in the workplace: the effects of organizational structures, processes, practices, and decision makers' sexism. Frontiers in psychology, v. 6, n.1400, p. 1-20, 2015. Disponível em: https://www.frontiersin.org/articles/10.3389/fpsyg.2015.01400/full Acesso em: 14 abr. 2020. 
UFMS - UNIVERSIDADE FEDERAL DE MATO GROSSO DO SUL. Mulheres respondem por metade da força de trabalho em ensino e produção científica na UFMS. Campo Grande, 2017. Disponível em: https:/www.ufms.br/mulheres-respondem-por-metade-da-forca-de-trabalho-emensino-e-producao-cientifica-na-ufms/. Acesso em: 23 set. 2020.

UNICAFES - UNIÃO DAS COOPERATIVAS DA AGRICULTURA FAMILIAR E ECONOMIA SOLIDÁRIA. Página inicial. Brasília, 2020. Disponível em: http://unicafes.org.br. Acesso em: 14 nov. 2020.

PNUD. Programa das Nações Unidas para o Desenvolvimento. Objetivos de Desenvolvimento Sustentável. 2015. Disponível em:https://www.br.undp.org/content/brazil/pt/home/sustainabledevelopment-goals.html. acesso em 10 nov. 2020.

VIGLIONE, G. Are women publishing less during the pandemic? Here's what the data say. Nature, Londres, News (online), 2020. Disponível em: https://www.nature.com/articles/d41586-020-01294-9. Acesso em: 21 mai. 2020.

ZIMMERMANN, S. A.; GARCIAS, M. DE O.; BASSO, D. Participación y empoderamiento de las mujeres en las cooperativas: un estudio sobre la participación de mujeres en cooperativas de la agricultura familiar en Brasil Women Participation and Empowerment. Desenvolvimento em Debate, v.8, n. 1, p. 145-161, 2020.

ZIOLKOWSKI, N. E. Mulheres à frente no Cerrado e Pantanal: o entrelaçar de força na prática da resistência. Revista Movimentação, Dourados, MS, v.5, n.10, jan./jun. 2019. Disponível em: http://ojs.ufgd.edu.br/index.php/movimentacao/article/view/10594. Acesso em: 30 mai. 2020. 